\title{
Öğrencilerin Üçlü Kodlama Modelinde Sunulan Sayısal Büyüklükleri Sayı Doğrusunda Tahminleri
}

\author{
Mehmet Hayri SARI', Sinan OLKUN ${ }^{2}$
}

\begin{abstract}
Öz: Bu araştırmada, ilkokul ikinci ve üçüncü sınıf öğrencilerinin üçlü kodlama modeline göre sunulan sayısal büyüklüklerin sayı doğrusunda tahmin becerilerinin matematik başarısı, aritmetik performansı ve basamak değeri kavrayışı ile ilişkisi incelenmiştir. Araştırmanın verileri, matematik başarı testi (MBT), aritmetik performans testi (APT), basamak değeri testi (BD) ve bilgisayar yazılımı olarak hazırlanan sayı doğrusunda tahmin testleri (SDT) ile toplanılmıştır. Bilgisayar ortamındaki testler araştırmacılar tarafından geliştirilmiş olup üçlü kodlama modeline göre tasarlanan sembolik, sözel ve görsel (kanonik ve rastgele çokluklar) kodlardan ve 0-10 ile 0-100 sayısal aralıklardan oluşmaktadır. Araştırmanın çalışma grubunu İç Anadolu Bölgesi'nde bulunan bir ilden toplam 214 ikinci ve üçüncü sınıf öğrencisi oluşturmuştur. Bulgular, üçüncü sınıf öğrencilerinin tüm testlerde sayı doğrusu üzerinde tahminlerinin ikinci sınıf öğrencilerine göre daha doğrusal olduğunu göstermektedir. Her sınıf düzeyinde MB testine göre belirlenen alt ve üst başarı grubunda yer alan öğrencilerin başarısı APT, BD, SDT 0-10 ve 0-100 açısından farklılaşmaktadır. Bu farklılaşmanın özellikle APT ve BD testleri açısından daha belirgin olduğu görülmüştür. Üçüncü sınıfta alt ve üst gruplar arasındaki başarı farkı daha da açılmaktadır. Üçlü kod modeline göre tasarlanan 0-10 tahmin aralığındaki testlerden Sözel 0-10 ve Kanonik 0-10 matematik başarısını daha çok yordamaktadır. Basamak değeri kavrayışını en çok Sembol 0-10 yordarken, aritmetik performansını en çok Kanonik nokta sayılama 0-10 yordamaktadır. 0-100 aralığındaki tahmin testlerinde ise, matematik başarısını en çok Sembol 0-100 yordarken, basamak değeri kavrayışını da Sembol 0-100 ve Rastgele nokta sayılama testleri yordamaktadır. Farklı temsil biçimleri ile öğretimin çocukların kapsamlı matematik kavrayışları açısından daha yararlı olacağı sonucuna varılabilir.
\end{abstract}

Anahtar Sözcükler: Basamak değeri, İlkokul, Matematik başarısı, Sayı doğrusunda tahmin, Üçlü kodlama

\section{Students' Number Line Estimations of Numerical Magnitudes Presented in Triple Coding Model}

\begin{abstract}
The purpose of this study was to investigate primary school students' estimations of number magnitudes on number lines in relation to their mathematics achievement, calculation performance, and place value understanding. The data were collected by mathematics achievement test (MAT), arithmetic performance test (APT), place value test (PVT) and computerized number line estimation tests (NLE). Computerized tests were developed by the researchers and consist of symbolic, verbal and visual (canonical and random dots) codes within 0-10 and 0-100 range designed according to the triple coding model. The study group consisted of 214 second and third grade students drawn from a city in the Central Anatolia Region. Results showed that the estimation skills of third grade students in all tests on the number lines are more linear than that of the second-grade students. The success of students in the lower and upper achievement groups determined according to the mathematics achievement test at each grade level differs in terms of APT, PVT, NLE 0-10 and 0-100. It was observed that this differentiation was more pronounced in terms of APT and PVT tests. The higher the grade level, the wider the difference in achievements between the lower and upper groups. The Verbal 0-10 and Canonical 0-10 tests, which were designed according to the triple code model, predict mathematics achievement more than other tests within $0-10$ range. While Symbol 0-10 test predicts the comprehension of place value most, Canonical Dot Enumeration test is the most predictor of arithmetic performance. Looking at the tests in the range of 0-100, Symbol 0-100 predicts mathematics achievement the most, while Symbol 0-100 and Random Dot Enumeration test predict place value comprehension. Based on these results, it can be concluded that using different forms of numerical representations will be more beneficial for children's thorough understanding of mathematics.
\end{abstract}

Keywords: Place value, Primary school, Math achievement, Number line estimation, Triple coding

\author{
Geliş Tarihi: 22.04 .2021 \\ Kabul Tarihi: 09.06.2021 \\ Makale Türü: Araştırma Makalesi \\ ${ }^{1}$ Nevşehir Hacı Bektaş Veli Üniversitesi, Eğitim Fakültesi, Temel Eğitim Bölümü, Nevşehir, Türkiye, e-posta: $\underline{\text { mhsari@nevsehir.edu.tr }}$ \\ ORCID: https://orcid.org/0000-0002-7159-2635 \\ 2 Uluslararası Final Üniversitesi, Eğitim Bilimleri Fakültesi, Matematik ve Fen Bilimleri Eğitimi Bölümü, Girne, KKTC, e-posta: sinan.olkun@final.edu.tr \\ ORCID: https://orcid.org/0000-0003-3764-2528
}


Matematiksel düşüncenin gelişiminde, çalışma belleği, işlem hızı gibi genel becerilerin yanı sıra matematiğe özel bazı temel becerilerin geliştirilmesi de gerekir. Örneğin; sembolik olmayan çoklukların karşılaştırılması, sembolik miktarları karşılaştırma, kod dönüştürme, sayma becerileri, tek basamaklı aritmetik gibi temel beceriler; çok basamaklı aritmetik işlemlerin geliştirilmesi, basamak değeri, kavramsal ve işlemsel kesir bilgisi, orantısal akıl yürütme, matematiksel denklik gibi daha ileri düzey matematiksel becerilerin gelişiminde temel oluşturur (Berch, Geary ve Koepke, 2016). Sayılan bu erken aritmetik becerileri, öncelikle çocukların sözel sayma, sıralı sayma, sayılarla çoklukları ilişkilendirme ve basamaklara ait büyüklükleri anlamalarına yardımcı olur. Bu temel becerilerden bir tanesi de rakamları yazılı olarak anlama ve sözel kodla ilişkilendirmedir (Long, 2019). Söz konusu bu beceriler, Dehaene (1992) tarafından Üçlü Kod Modeli (Triple Coding Model) ile ortaya konulmuştur.

Sayısal bilişin Üçlü Kod Modeli, sayı için üç temel temsili kodun varlığını savunmaktadır: Bunlar analog, sözel ve sembolik temsillerdir (Dehaene, 1992). Bu temsillerin ilkinde sayı görsel olarak benzer büyüklük ya da çokluk bilgisi ile temsil edilmektedir. Örneğin, doğum günü pastasındaki mumlar, konserde bulunan 700 insan gibi. Tüm bunlar sayı hissini bize hatırlatmaktadır. İkinci temsil biçiminde ise konuşma ve yazı biçimi kullanılır. Örneğin, "on beş” gibi sayısal bir büyüklüğün sözcüklerle ifade edilmesidir. Üçüncü kod ise sembolik formattır (burada rakam formatı). Büyüklük ya da miktar bir sembolle temsil edilir. Örneğin 3, 8 gibi tek haneli sayılar ya da 632 gibi çok basamaklı sayılar rakamlar kullanılarak belli kurallarla kodlanır (Landerl, 2019).

Bilişsel sinirbilimde yaygın olarak "sayı hissi" olarak adlandırılan ilk sistem olan analog büyüklükleri temsil sistemi, bir sayı doğrusundaki sayılar arasında uzaklık ilişkilerinin sözel olmayan anlamsal bir temsilini kullanır. Miktar karşılaştırmaları (örneğin daha çok veya daha az) ve yaklaşık tahmin görevleri bu ilk sistemde gerçekleşir. İkinci sistem olan sözel sistem ise sayıları sözel formatta, yani sözcüksel, fonolojik ve sözdizimsel olarak temsil eder. Bu sistem öncelikle sayıların sözel olarak söylenmesinde daha sonra da toplama ve çarpım tabloları gibi aritmetik gerçekler öğrenilirken devreye girer ve aritmetik gerçeklerin geri çağrılmasını sağlar. Üçüncü sistemde ise, sayıların görsel sembolle temsil görevi gerçekleştirilir. Bu sistemde basamak değeri kavramı gibi ek notasyonlarla daha büyük sayılar da aynı sembollerle temsil edilir (Canto-Lopez ve diğerleri, 2021; Looi, Thompson, Krause ve Cohen Kadosh, 2016; Soares, Evans ve Patel, 2018). Özetle üçlü kod modeli içerisinde yer alan analog büyüklük kodu, yaklaşık hesaplama, tahmin ve sayı büyüklükleri karşılaştırmalarını destekler. Ayrıca şipşak sayılamada (subitizing) önemli bir role sahiptir. Çok basamaklı işlemlere rakamsal sayı formları aracılık ederken, işitsel ve sözel yazılı kod temsili basit toplama ve çarpma gerçekleri için temel sağlar (Campbell ve Epp, 2005).

Dehaene ve Cohen (1995), bu üç kod ile yapılan sayısal ve matematiksel işlemlerin beyinde işlevsel ve yapısal olarak birbirinden ayrıldığını iddia etmektedir. Başka bir deyişle, bu kodlar anatomik olarak farklı beyin bölgelerini aktive etmekte ve birbirinden bağımsız olarak işlev görebilmektedir (Ansari, 2010). Benzer şekilde Peters, Polspoel, Op de Beeck ve De Smedt (2016) tarafından yapılan bir araştırmada, sembolik ve sembolik olmayan formatlarla hesaplama sırasında beynin farklı bölgelerinin işlev gördügü bulunmuştur. Çalışmada sembolik (rakamlar, sayı sözcükleri) ve sembolik olmayan (nokta dizileri) sunum formatlarında hesaplama sırasında beyin aktivitesi araştırılmıştır. Her üç formatın da oksipito-parietal bölgeleri, insula lobunu ve singulat korteksi aktive ettiği rapor edilmiştir. Ayrıca fusiform girusta (yani, görsel sözcük form alanı) sayı sözcükleri için ek aktivite bulunmuştur (Peters ve diğerleri, 2016). Yetişkinlerde yapılan benzer bir çalışmada (Peters, De Smedt ve Op de Beeck, 2015), görsel kelime form alanındaki aktivitenin sayı sözcükleri için rakam ve nokta dizilerinden daha yüksek olduğu gözlemlenmiştir. Bununla birlikte, bu çalışmada nokta dizileri veya rakamlardan ziyade, sayı sözcükleri için fiksasyona karşı sadece ek görsel sözcük form alanı etkinliği bulunmuştur. Son olarak, nokta dizileri frontal bölgelerde daha fazla beyin aktivasyonu sağlamıştır. Bunun da muhtemelen çalışma belleğine ve dikkat süreçlerine artan güveni yansıtabileceği iddia edilmiştir (Peters ve diğerleri, 2015).

Üç formatın birbiriyle doğrudan karşılaştırılması, her iki sembolik formatın (rakam ve sözcük), sayı sözcükleri için ek birincil görsel korteks aktivasyonu haricinde, aynı sinir bölgelerini topladığını göstermiştir. Bununla birlikte, araştırmacılar bunun, kullanılan uyaranların görsel özellikleri ile açıklanabileceğini öne 
sürmüşlerdir. Zira, sayı sözcükleri, doğası gereği, rakamlardan daha görsel öğelerden (çizgiler ve bireysel karakterler) oluşan daha karmaşık görsel uyaranlardır (Peters ve diğerleri, 2016).

Sözlü olarak desteklenen sembolik sayı bilgisi ve sözel veya sembolik olmayan büyüklük gösterimlerinin birleşimi, Üçlü Kod Modelinde yansıtıldığı gibi tipik sayısal becerilerin temelini oluşturmaktadır (Skagenholt, Träff, Västfjäll ve Skagerlund, 2018). Gelişim ve öğrenmeyle ilgili veriler de küçük çocukların, yazılı rakamları anlamadan önce sözel sayı kelimelerini miktarlarla ilişkilendirmeyi öğrendiklerini (Fayol ve Seron, 2005) benzer şekilde sözel ve görsel kodların işlevsel olarak farklı olduğunu göstermektedir (Skagenholt ve diğerleri, 2018).

Üçlü kodlama modeli, çocuk ve yetişkinlerde sayısal büyüklüğü temsil eden zihinsel sayı doğrusunun önemini vurgulamaktadır (Canto-Lopez ve diğerleri, 2021). Üçlü kod modeli, matematik başarı ve performansını değerlendirmek için farklı yaklaşımlara zemin hazırlamaktadır. Bugüne kadar araştırmaların en yoğun ilgisini büyüklük karşılaştırmaları ve yaklaşık tahmin görevlerini içeren analog büyüklük temsili görevleri oluşturmuştur (Peters ve diğerleri, 2016). Bu nedenle üçlü kodlama modelinde yer alan sözel, analog ve sembolik temsil görevlerinin her üçünü birden içeren testler karşısında çocukların matematik başarısı, aritmetik performansları ve basamak değeri kavrayışlarıyla ilişkisinin ortaya konulması bilgimiz dâhilinde henüz yapılmamıştır. Çalışmada elde edilecek verilerin öğretimsel materyal geliştirme çalışmalarına ışık tutacağı düşünülmektedir.

\section{Yöntem}

\section{Çalışma Grubu}

Araştırmanın çalışma grubunu, Türkiye'nin İç Anadolu Bölgesinde yer alan bir il merkezinde orta-sosyo ekonomik düzeye sahip bir okulun tüm 2. ve 3.sınıfları oluşturmuştur. 2. ve 3. sınıfın temel matematiksel yeteneklerin gelişimi için önemli bir dönem olması ( $\mathrm{Wu}$, Willcutt, Escovar ve Menon, 2014) ve öğrencilerin sınıfları ilerledikçe sembolik kodlara daha yatkın hale geleceği varsayımı nedeniyle araştırmada bu sınıf düzeyleri seçilmiştir. Aynı zamanda öğrenciler basamak değeri ile ilgili konuları 2. sınıfta görmeye başlamakta, 3. sınıfta da bu konulara devam etmektedirler. Araştırmada tüm testlere katılan 2. sınıf öğrenci sayısı 128 ve 3. sınıf öğrenci sayısı ise 141'dir. Analizlere geçmeden önce Raven Progressive Matrices (RPM) testinde en kötü performans gösteren \%15'lik dilim dışlanmıştır. Bu kişilerin araştırmadan dışlanmasındaki sebep ortalamanın altında zihinsel kapasite olarak tanımlanmalarıdır (Raven, Raven ve Court, 2004). Bu kapsamda 28 öğrenci araştırmadan çıkarılmıştır. Ayrıca elde edilen verilerin analizine geçmeden önce yapılan normallik testleri (z scores, mahalanobis distance vb.) kontrollerinde 27 öğrenciye ait puanlar veri setini bozduğu için dişlanmıştır. Araştırmada toplam 214 öğrencinin verisi kullanılmıştır. 2.sınıf öğrenci sayısı 90 (42,1\%) ve 3.sınıf öğrenci sayısı 124 (57,9\%)'tür. Toplam öğrencilerin 103'ü (48,1\%) erkek ve 111'i (51,9\%) kız öğrencidir.

\section{Veri Toplama Araçları}

Araştırmada veri toplama amacıyla toplam 5 farklı test kullanılmıştır. Testlere ait bilgiler aşağıda verilmiştir:

- Matematik Başarı Testi (MAT): Fidan (2013) tarafından geliştirilmiş olup sayılar öğrenme alanını (sayılar, sayma, sayı örüntüleri, aritmetik işlemler ve kesirler) içeren başarı testidir. Testin KR-20 güvenilirlik katsayısı ikinci sınıflar için 0.92, üçüncü sınıflar için ise 0.96 olarak bulunmuştur. Öğrencilere test için bir ders saati (40 dakika) süre verilmiştir.

- Aritmetik Performans Testi (APT): De Vos (1992) tarafından geliştirilen ve Olkun, Can ve Yeşilpınar (2013) tarafından Türkçe uyarlaması yapılan aritmetik işlemlerden (toplama, çıkarma, çarpma ve bölme) oluşan bir testtir. Her kolonda 40 tane olmak üzere 5 kolonda toplam 200 sorudan oluşmaktadır. Olkun ve arkadaşları (2013), kısıtlı süreli ve serbest süreli olarak uyguladıkları testin KR-20 güvenilirlik katsayılarını 0.95 ve 0.98 olarak bulmuşlardır. Bu araştırma için her bir sütunun uygulanmasında öğrencilere 1 dakika süre verilmiştir. 
- Basamak Değeri Testi (BD): Öğrencilerin basamak değeri kavrayışlarını ölçmek için uygulanan basamak değeri testi, Herzog, Fritz ve Ehlert (2017) tarafından geliştirilmiş olup Sarı, Herzog, Olkun ve FritzStratmann (t.y) Türkçeye uyarlama yapmıştır. Her bir sınıf düzeyi için testte toplam 36 soru vardır. Tek boyutlu bir Rasch analizinde maddeler, çoğunlukla (\% 88.2) modelin öngördüğü gibi hizalanmış ve tutarlı zorluk seviyeleri oluşturmuştur. Uyarlanan sınav, Türkçe "Basamak Değeri Testleri" ile (Mutlu ve Sarı, 2019; Sarı ve Olkun, 2019; Paydar ve Sarı, 2019) anlamlı bir korelasyon göstermiştir (r=.762; 464; 688, $\mathrm{p}<.001)$. Öğrencilere test için bir ders saati (40 dakika) süre verilmiştir.

- RAVEN Standart Progresive Matrisler PLUS testi: RAVEN testi, analitik irdelemeyi, problem çözmeyi, düzenli düşünmeyi ve soyutlama ile zihinsel faaliyet hızını ölçmektedir. RAVEN SPM testi, her biri 12 sorudan ve 5 adet setten (A, B, C, D, E) oluşmaktadır. Her bir soruda bir kısmı eksik olan şeklin verilen seçeneklerden biri ile tamamlanmasından oluşmaktadır. Bu test için uygulama süresi 50 dakikadır.

- Zihinsel Sayı Doğrusu Testi: Araştırmada sembol, sözel, kanonik (düzenli dizilmiş) ve rastgele noktalarda sayılar içeren sayı doğrusu testi kullanılmıştır. 0-10 ve 0-100 olmak üzere iki farklı sayı doğrusu aralığı kullanılmıştır. Testlerden örnek görüntüler Şekil 1-4'te paylaşılmıştır. 0-10 aralığındaki sayı doğruları için 11 tane ve 0-100 aralığındaki sayı doğrusu için 16 tane soru sorulmuştur. Çocukların verdiği cevaplar Excel veri tabanında kayıt altına alınmıştır.

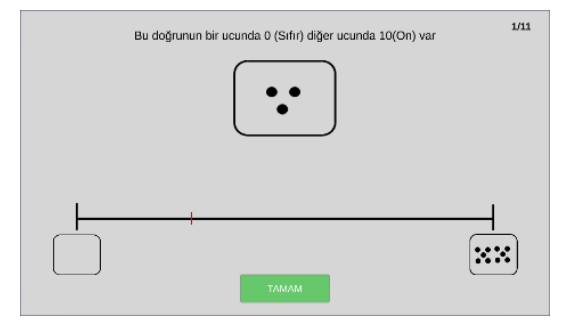

Şekil 1. 0-10 kanonik dizilmiş noktalar

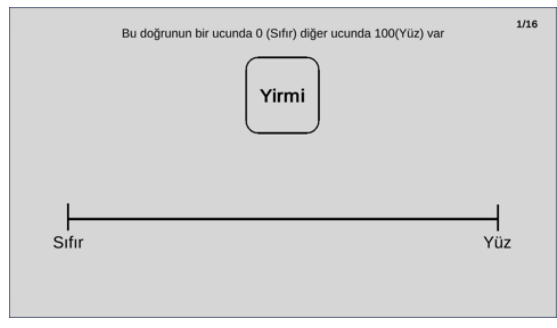

Şekil 3. 0-100 sözel kod temsil

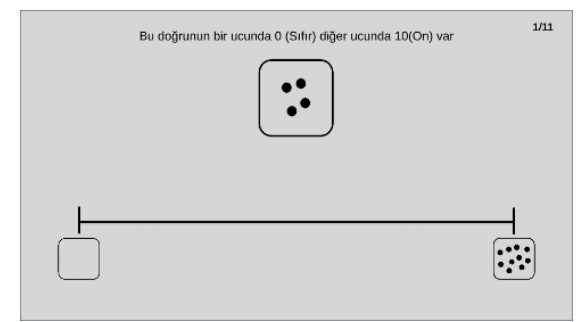

Şekil 2. 0-10 rastgele dizilmiş noktalar

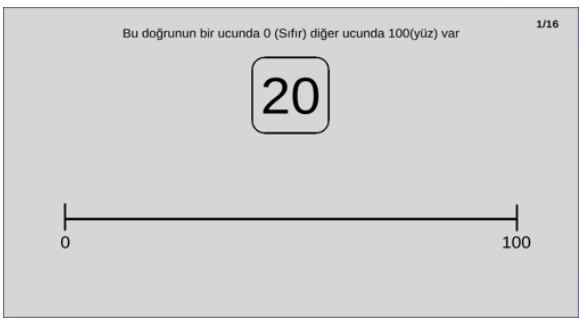

Şekil 4. 0-100 sembol kod temsil

\section{Verilerin Analizi}

Verilerin analizine geçmeden önce her bir testte yer alan puanlar " $=\left(((\mathrm{X} \max -\mathrm{X} \min ) /(\mathrm{Ymax}-\mathrm{Y} \min ))^{*}(\mathrm{~V}-\right.$ $Y \max ))+X \max "$ formülü ile standart 100 puana dönüştürülmüştür. Yapılacak analizlere karar vermeden önce test puanlarının normallik varsayımını karşılayıp karşılamadığı skewness ve kurtosis değerleri ile incelenmiştir. Ayrıca her bir testin Z skorları hesaplanmıştır. Her sınıf düzeyinde bütün testlere ait ortalama ve standart sapma değerleri hesaplanmıştır. Regresyon analizine geçmeden önce testler arasındaki Pearson korelasyon katsayısı hesaplanmıştır. Regresyon analizi için varsayımlara (mahalanobis uzaklıkları, variance inflation factor (VIF) değeri, Durbin-Watson katsayısı, Cook's uzaklıkları) bakılmıştır. Varsayımlar sonrasında matematik başarısı, aritmetik performansı ve basamak değeri kavrayışını hangi üçlü kod türünün daha çok yordadığını ortaya koymak için çoklu doğrusal regresyondan stepwise analizi türü tercih edilmiştir. Ayrıca her sınıf düzeyinde çocukların matematik başarı testi ve RAVEN testi skorları alt ve üst \%25 grup olacak şekilde ikiye ayrılmıştır. Araştırmada \%25'lik dilimin kesim noktası olarak kullanılmasının nedeni; genellikle çocukların alt grupta yer alan \%25'lik kesimin matematik öğrenmede zorluk yaşadığı (Geary, Hoard, Byrd- 
Craven, Nugent ve Numtee, 2007) ve araştırmacıları \%25'lik dilimin altındaki tüm çocuklara belirli bir matematik öğrenme riskli grup olarak değerlendirilebileceğini söylemektedirler (Berteletti ve Booth, 2016). Alt-üst \%25 olarak oluşturulan iki grup kendi aralarında aritmetik performansları, basamak değeri kavrayışları, sembol, sözel ve analog sayı doğrusu tahmin testlerinden aldıkları ortalama puanlar açısından farklılaşıp farklılaşmadıkları bağımsız örneklemler (independent samples) t-testi ile karşılaştırılmıştır. Çocukların sayı doğrusu testinden elde ettikleri tahmin hata miktarları ise Siegler ve Booth (2004) tarafından önerilen "|Estimations - to be estimated number)/scalel" formülü ile hesaplanmıştır. Ayrıca alt-üst 25'lik grupların sayı doğrusu tahminlerine ait medyan değerleri bulunarak R-kare $\left(R^{2}\right)$ değerleri hesaplanmış ve logaritmik, üstel ya da doğrusal grafiklerden hangisine daha çok uydukları belirlenmiştir.

\section{Bulgular}

İlkokul 2. ve 3.sınıf öğrencilerinin testlerden almış oldukları ortalama puanlar sınıf düzeyi değişkeni açısından karşılaştırıldığında, Sembol 0-100 [t(212) = -1.580, p> .05] ve Kanonik 0-10 [t(212) = -1.135, p> .05] testlerinde anlamlı bir farklılık görülmemektedir (Tablo 1). Buna karşın, Sembol 0-10 [t(212) = -4.775, p<.05], Sözel 0-10 [t(212) $=-2.542, \mathrm{p}<.05]$, Sözel 0-100 [t(212) $=-3.503, \mathrm{p}<.05]$, Rastgele noktalar 0-10 [t(212) $=-2.696$, $\mathrm{p}<.05]$, Rastgele noktalar 0-100 [t(212) $=-4.326, \mathrm{p}<.05]$ ile Kanonik noktalar 0-100 [t $(212)=-6.274, \mathrm{p}<.05]$ testi ortalama puanlar açısından karşılaştıııldığında sınıf düzeyi açısından anlamlı bir farklılık vardır (Tablo 1). Bu anlamlı fark bütün testlerde 3.sınıf öğrenciler lehinedir. 2. ve 3.sınıf öğrencilerinin üçlü kodlama testlerine ait büyüklük tahminleri değişim grafiği Şekil 5'te verilmiştir.

Tablo 1. Sınıf Düzeylerine Göre Ö̆grencilerin Test Puan Ortalamaları Açısından Karşılaştırılmasına Ait Sonuçlar

\begin{tabular}{|c|c|c|c|c|c|c|c|}
\hline Değişkenler & Sinif & $\mathrm{N}$ & $\bar{X}$ & S.D & $\mathrm{df}$ & $\mathrm{t}$ & $\mathrm{p}$ \\
\hline \multirow{2}{*}{ Sembol 0-10 } & İkinci & 90 & 63,58 & 16,12 & \multirow{2}{*}{212} & \multirow{2}{*}{-4.775} & \multirow{2}{*}{$.001^{*}$} \\
\hline & Üçüncü & 124 & 74,47 & 16,91 & & & \\
\hline \multirow{2}{*}{ Sembol 0-100 } & İkinci & 90 & 81,51 & 11,49 & \multirow{2}{*}{212} & \multirow{2}{*}{-1.580} & \multirow{2}{*}{.116} \\
\hline & Üçüncü & 124 & 84,08 & 12,07 & & & \\
\hline \multirow{2}{*}{ Sözel 0-10 } & İkinci & 90 & 68,04 & 16,82 & \multirow{2}{*}{212} & \multirow{2}{*}{-2.542} & \multirow{2}{*}{$.012^{*}$} \\
\hline & Üçüncü & 124 & 73,79 & 15,60 & & & \\
\hline \multirow{2}{*}{ Sözel 0-100 } & İkinci & 90 & 77,87 & 11,86 & \multirow{2}{*}{212} & \multirow{2}{*}{-3.503} & \multirow{2}{*}{$.001^{*}$} \\
\hline & Üçüncü & 124 & 83,56 & 11,52 & & & \\
\hline \multirow{2}{*}{ Rastgele noktalar 0-10 } & İkinci & 90 & 59,82 & 22,35 & \multirow{2}{*}{212} & \multirow{2}{*}{-2.696} & \multirow{2}{*}{$.007^{*}$} \\
\hline & Üçüncü & 124 & 67,97 & 21,10 & & & \\
\hline \multirow{2}{*}{ Rastgele noktalar 0-100 } & İkinci & 90 & 69,27 & 13,86 & \multirow{2}{*}{212} & \multirow{2}{*}{-4.326} & \multirow{2}{*}{$.001^{*}$} \\
\hline & Üçüncü & 124 & 77,37 & 13,00 & & & \\
\hline \multirow{2}{*}{ Kanonik noktalar 0-10 } & İkinci & 90 & 64,33 & 21,77 & \multirow{2}{*}{212} & \multirow{2}{*}{-1.135} & \multirow{2}{*}{.258} \\
\hline & Üçüncü & 124 & 67,96 & 24,88 & & & \\
\hline \multirow{2}{*}{ Kanonik noktalar 0-100 } & İkinci & 90 & 68,76 & 15,17 & \multirow{2}{*}{212} & \multirow{2}{*}{-6.274} & \multirow{2}{*}{$.000^{*}$} \\
\hline & Üçüncü & 124 & 80,33 & 11,77 & & & \\
\hline
\end{tabular}

Her sınıf, kendi içerisinde olacak şekilde matematik başarısı (MBT) ve Raven testinden almış oldukları puan ortalamalarına göre alt ve üst \%25 başarı gruplarına ayrılmıştır. Ayrılan grupların tüm testlerden aldıkları ortalama puanlar bağımsız örneklemler t-testi analizi ile karşılaştırılmıştır. Yapılan analizlere ait sonuçlar Tablo 2' de ve Tablo 3'te verilmiştir. 
Öğrencilerin Üçlü Kodlama Modelinde Sunulan Sayısal ...

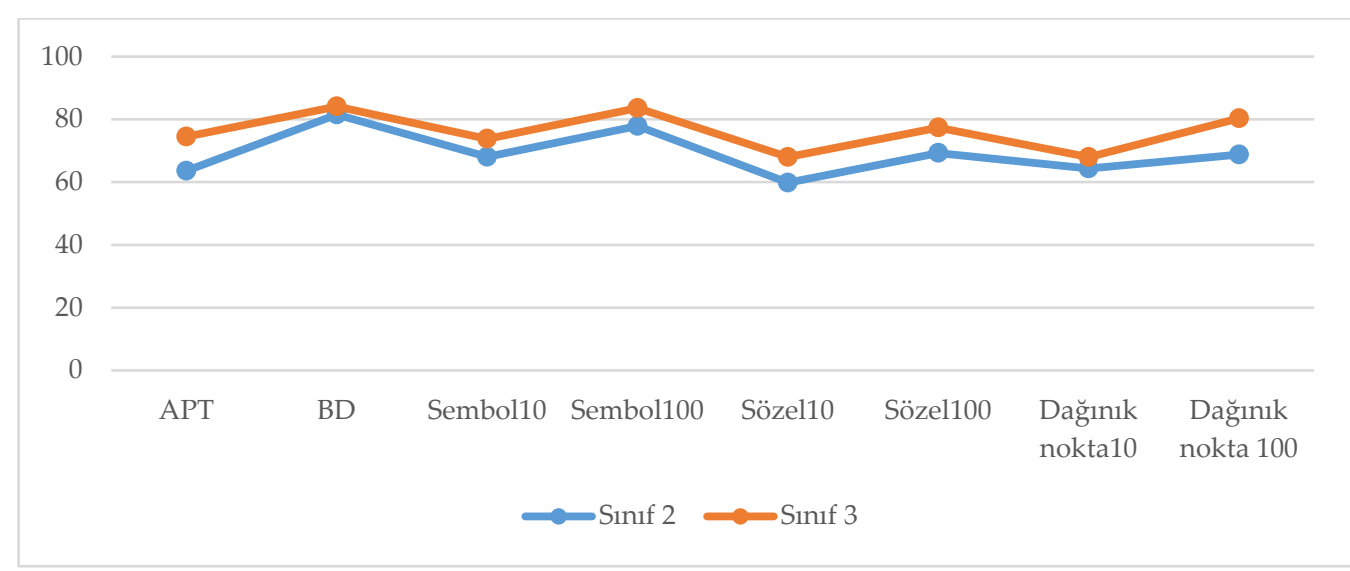

Şekil 5. Üçlü kodlama modelinde büyüklük tahminleri

Tablo 2. İkinci Sınıf Alt ve Üst Grup Ö̆grencilerinin Test Puan Ortalamaları Açısından Karşılaştırılmasına Ait Sonuçlar

\begin{tabular}{|c|c|c|c|c|c|c|c|}
\hline Değişkenler & Grup & $\mathrm{N}$ & $\bar{X}$ & S.D & $\mathrm{df}$ & $t$ & $\mathrm{p}$ \\
\hline \multirow{2}{*}{ APT } & Alt & 24 & 44,58 & 17,5 & \multirow{2}{*}{42} & \multirow{2}{*}{-6.440} & \multirow{2}{*}{$.001^{*}$} \\
\hline & Üst & 20 & 77,45 & 16,2 & & & \\
\hline \multirow{2}{*}{ BD } & Alt & 24 & 53,04 & 13,7 & \multirow{2}{*}{42} & \multirow{2}{*}{-4.771} & \multirow{2}{*}{$.001^{*}$} \\
\hline & Üst & 20 & 73,25 & 14,1 & & & \\
\hline \multirow{2}{*}{ Sembol 0-10 } & Alt & 24 & 58,91 & 13,3 & \multirow{2}{*}{42} & \multirow{2}{*}{-2.723} & \multirow{2}{*}{$.001^{*}$} \\
\hline & Üst & 20 & 72,45 & 18,5 & & & \\
\hline \multirow{2}{*}{ Sembol 0-100 } & Alt & 24 & 77,50 & 10,3 & \multirow{2}{*}{42} & \multirow{2}{*}{-4.027} & \multirow{2}{*}{$.010^{\circ}$} \\
\hline & Üst & 20 & 88,70 & 8,11 & & & \\
\hline \multirow{2}{*}{ Sözel 0-10 } & Alt & 24 & 61,58 & 14,6 & \multirow{2}{*}{42} & \multirow{2}{*}{-2.850} & \multirow{2}{*}{$.007^{\circ}$} \\
\hline & Üst & 20 & 76,40 & 19,0 & & & \\
\hline \multirow{2}{*}{ Sözel 0-100 } & Alt & 24 & 71,79 & 10,9 & \multirow{2}{*}{42} & \multirow{2}{*}{-3.392} & \multirow{2}{*}{$.002^{\prime}$} \\
\hline & Üst & 20 & 83,00 & 10,8 & & & \\
\hline \multirow{2}{*}{ Rastgele noktalar 0-10 } & Alt & 24 & 51,45 & 23,2 & \multirow{2}{*}{42} & \multirow{2}{*}{-3.017} & \multirow{2}{*}{$.004^{3}$} \\
\hline & Üst & 20 & 72,60 & 23,0 & & & \\
\hline \multirow{2}{*}{ Rastgele noktalar 0-100 } & Alt & 24 & 65,33 & 14,0 & \multirow{2}{*}{42} & \multirow{2}{*}{-2.513} & \multirow{2}{*}{$.016^{*}$} \\
\hline & Üst & 20 & 75,15 & 11,8 & & & \\
\hline \multirow{2}{*}{ Kanonik noktalar 0-10 } & Alt & 24 & 55,41 & 21,6 & \multirow{2}{*}{42} & \multirow{2}{*}{-3.171} & $000 *$ \\
\hline & Üst & 20 & 76,25 & 21,6 & & & .000 \\
\hline & Alt & 24 & 65,04 & 15,3 & & P & \\
\hline NanOHIK HOKtalar U-100 & Üst & 20 & 77,85 & 14,7 & 42 & -2.009 & .000 \\
\hline
\end{tabular}
${ }^{*} \mathrm{p}<.05$

2.sınıf düzeyinde tüm testlerden alınan puan ortalamaları alt-üst grup açısından karşılaştırıldığında (Tablo 2) anlamlı düzeyde farklılaştı̆̆ görülmektedir (APT [t(42) = -6.440, p<.05], BD [t(42) = -4.771, p<.05], Sembol 0-10 [t(42) = -2.723, p<.05], Sembol 0-100 [t(42) = -4.027, p<.05], Sözel 0-10 [t(42) = -2.850, p<.05], Sözel 0-100 [ $\mathrm{t}(42)=-3.392, \mathrm{p}<.05]$, Rastgele noktalar 0-10 [ $\mathrm{t}(42)=-3.017, \mathrm{p}<.05]$, Rastgele noktalar 0-100 [ $\mathrm{t}(42)=-2.513$, $\mathrm{p}<.05]$, Kanonik noktalar 0-10 [ $\mathrm{t}(42)=-3.171, \mathrm{p}<.05]$ ve Kanonik noktalar 0-100 [t(42) = -2.809, $\mathrm{p}<.05])$. Tüm testlerde üst grupta yer alan öğrenciler daha başarılıdır. Ortalamalara bakıldı̆̆ında özellikle aritmetik 
performansı ve basamak değeri anlayışında gruplar arasındaki farkın çok fazla olduğu görülmektedir (Bkz. Şekil 6).

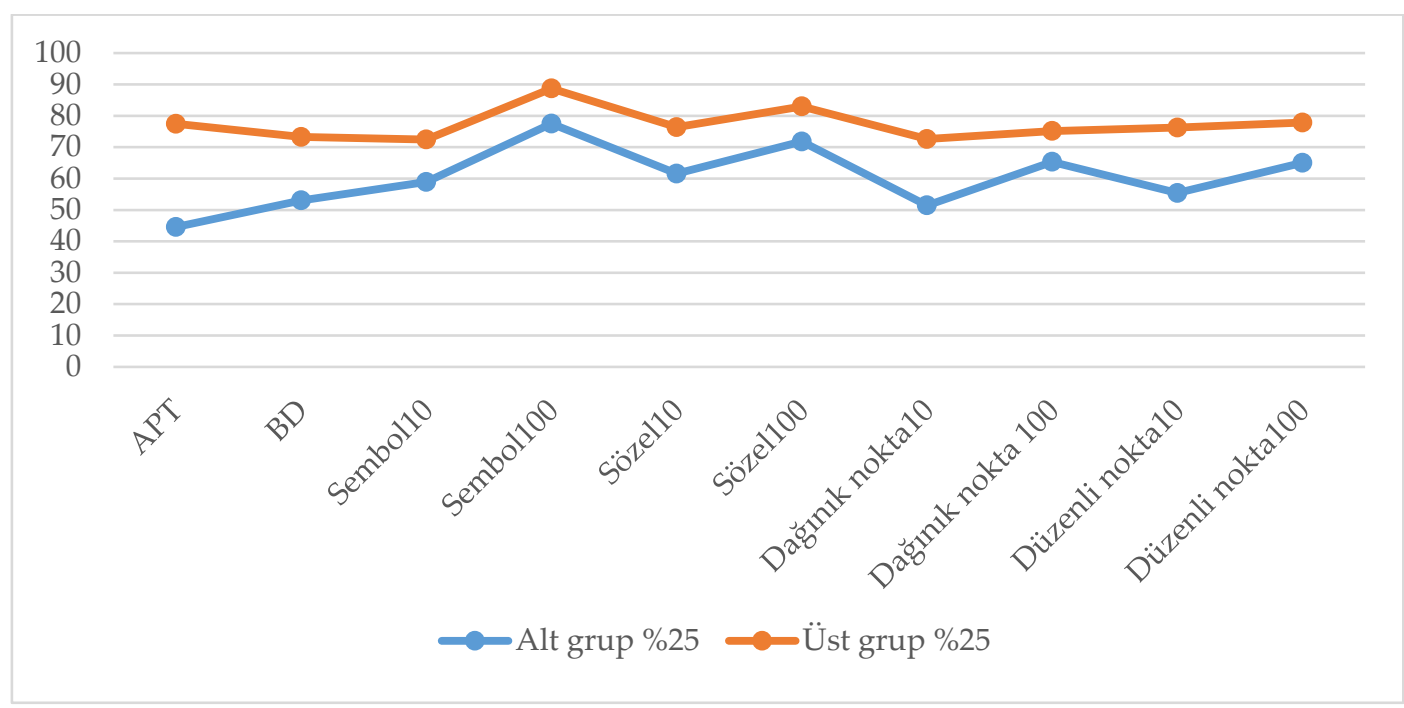

Şekil 6. İkinci sınıf alt ve üst grupların başarı testleri açısından karşılaştırılması

Tablo 3. Üçüncü Sinıf Alt ve Üst Grup Öğrencilerinin Test Puan Ortalamaları Açısından Karşılaştırılmasına Ait Sonuçlar

\begin{tabular}{|c|c|c|c|c|c|c|c|}
\hline Değişkenler & Grup & $\mathrm{N}$ & $\bar{X}$ & S.D & $\mathrm{df}$ & $\mathrm{t}$ & $\mathrm{p}$ \\
\hline \multirow{2}{*}{ APT } & Alt & 42 & 27,33 & 10,2 & \multirow{2}{*}{78} & \multirow{2}{*}{-12.117} & \multirow{2}{*}{$.001^{*}$} \\
\hline & Üst & 38 & 69,73 & 19,2 & & & \\
\hline \multirow{2}{*}{$\mathrm{BD}$} & Alt & 42 & 47,52 & 20,2 & \multirow{2}{*}{78} & \multirow{2}{*}{-7.840} & \multirow{2}{*}{$.001^{*}$} \\
\hline & Üst & 38 & 80,13 & 16,5 & & & \\
\hline \multirow{2}{*}{ Sembol 0-10 } & Alt & 42 & 64,80 & 17,6 & \multirow{2}{*}{78} & \multirow{2}{*}{-6.300} & \multirow{2}{*}{$.001^{*}$} \\
\hline & Üst & 38 & 85,81 & 11,8 & & & \\
\hline \multirow{2}{*}{ Sembol 0-100 } & Alt & 42 & 80,40 & 12,9 & \multirow{2}{*}{78} & \multirow{2}{*}{-3.115} & \multirow{2}{*}{$.003^{*}$} \\
\hline & Üst & 38 & 88,28 & 9,59 & & & \\
\hline \multirow{2}{*}{ Sözel 0-10 } & Alt & 42 & 65,21 & 17,5 & \multirow{2}{*}{78} & \multirow{2}{*}{-5.563} & \multirow{2}{*}{$.001^{*}$} \\
\hline & Üst & 38 & 83,23 & 10,9 & & & \\
\hline \multirow{2}{*}{ Sözel 0-100 } & Alt & 42 & 79,04 & 12,2 & \multirow{2}{*}{78} & \multirow{2}{*}{-3.718} & \multirow{2}{*}{$.001^{*}$} \\
\hline & Üst & 38 & 88,07 & 9,43 & & & \\
\hline \multirow{2}{*}{ Rastgele noktalar 0-10 } & Alt & 42 & 57,35 & 22,1 & \multirow{2}{*}{78} & \multirow{2}{*}{-4.968} & \multirow{2}{*}{$.001^{*}$} \\
\hline & Üst & 38 & 79,89 & 17,9 & & & \\
\hline \multirow{2}{*}{ Rastgele noktalar 0-100 } & Alt & 42 & 72,78 & 13,2 & \multirow{2}{*}{78} & \multirow{2}{*}{-3.655} & \multirow{2}{*}{$.001^{*}$} \\
\hline & Üst & 38 & 82,44 & 9,93 & & & \\
\hline \multirow{2}{*}{ Kanonik noktalar 0-10 } & Alt & 42 & 53,47 & 27,8 & \multirow{2}{*}{78} & \multirow{2}{*}{-4.882} & $.001^{*}$ \\
\hline & Üst & 38 & 79,02 & 18,4 & & & .001 \\
\hline & Alt & 42 & 76,45 & 12,5 & 78 & -2.555 & $013^{*}$ \\
\hline Kanonik noktalar 0-100 & Üst & 38 & 82,84 & 9,45 & 78 & -2.555 & $.013^{\prime}$ \\
\hline
\end{tabular}

${ }^{*} \mathrm{p}<.05$

3.sınıfta yer alan çocuklar alt-üst \%25 başarı gruplarına göre testlerden aldıkları ortalama puanlar açısından karşılaştırıldığında ise (Tablo 3), alt grupta ve üst grupta yer alan öğrenciler tüm testlerden aldıkları ortalama puanlar açısından farklılaşmaktadır (APT [t(78) = -12,464, p<.05], BD [t(78) = -7,920, p<.05], Sembol 010 [t(78) = -2.723, p<.05], Sembol 0-100 [t(78) = -3,070, p<.05], Sözel 0-10 [t(78) = -5,442, p<.05], Sözel 0-100 [t(78) $=-3,670, \mathrm{p}<.05]$, Rastgele noktalar 0-10 [t(78) = -5,019, $\mathrm{p}<.05]$, Rastgele noktalar 0-100 [t(78) = -3,708, $\mathrm{p}<.05]$, Kanonik noktalar 0-10 [t(78) = -4,787, $\mathrm{p}<.05]$ ve Kanonik noktalar 0-100 [t $(78)=-2.555, \mathrm{p}<.05])$. Üst grupta yer alan öğrenciler tüm testlerde daha başarılıdır. Hem 2.sınıf hem de 3.sınıf alt-üst gruplarında özellikle APT ve BD testleri açısından ortalamalar arasındaki başarı farkının oldukça belirgin olduğu görülmüştür. Özellikle sınıf seviyesi arttıkça alt ve üst gruplar arasındaki başarı farkının daha da açıldığı söylenebilir (Bkz. Şekil 7). 


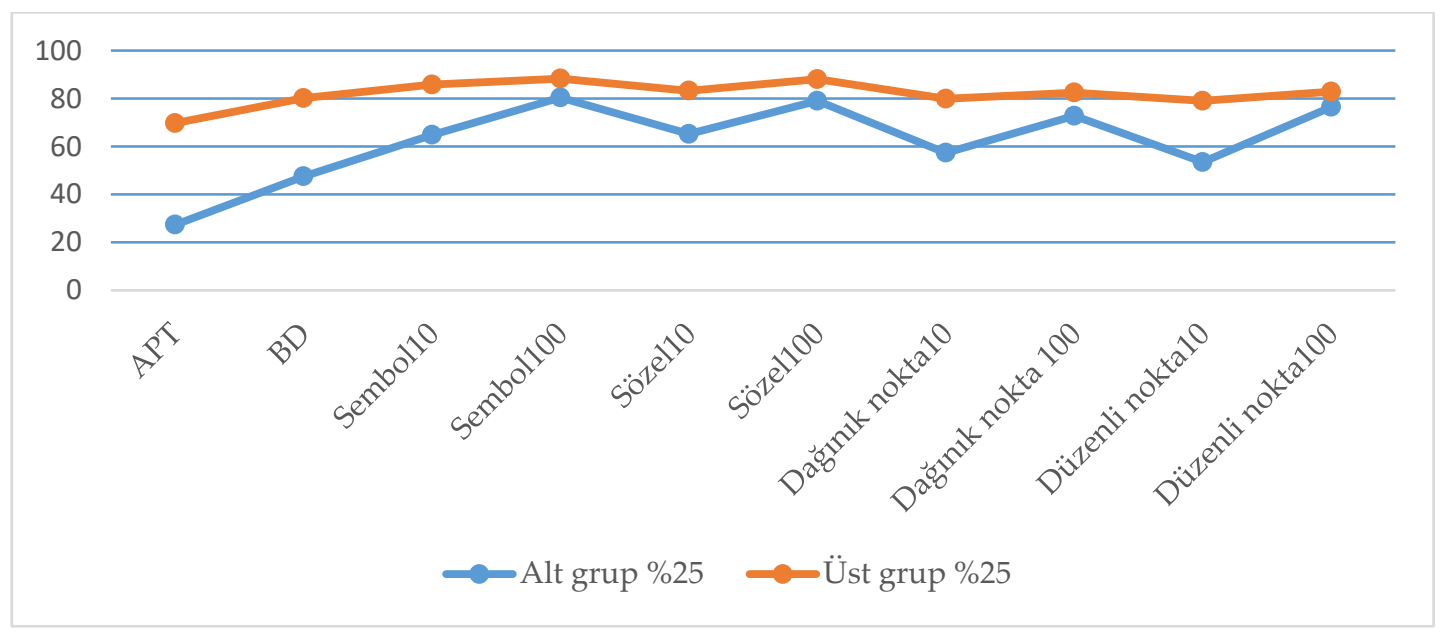

Şekil 7. Üçüncü sınıf alt ve üst grupların başarı testleri açısından karşılaştırılması

Araştırmada regresyon modelini kullanarak alt-üst \%25'lik grupların tahminlerinin uygunluğu karşılaştırılmıştır. Grupların sayı doğrusu tahminlerine ait medyan değerleri bulunarak R-kare değerleri hesaplanmıştır. Hesaplamalar sonucunda ikinci sınıf alt-üst \%25'lik gruplardaki öğrencilere ait ortaya çıkan grafikler Şekil 8, Şekil 9, Şekil 10 ve Şekil 11'de verilmiştir.
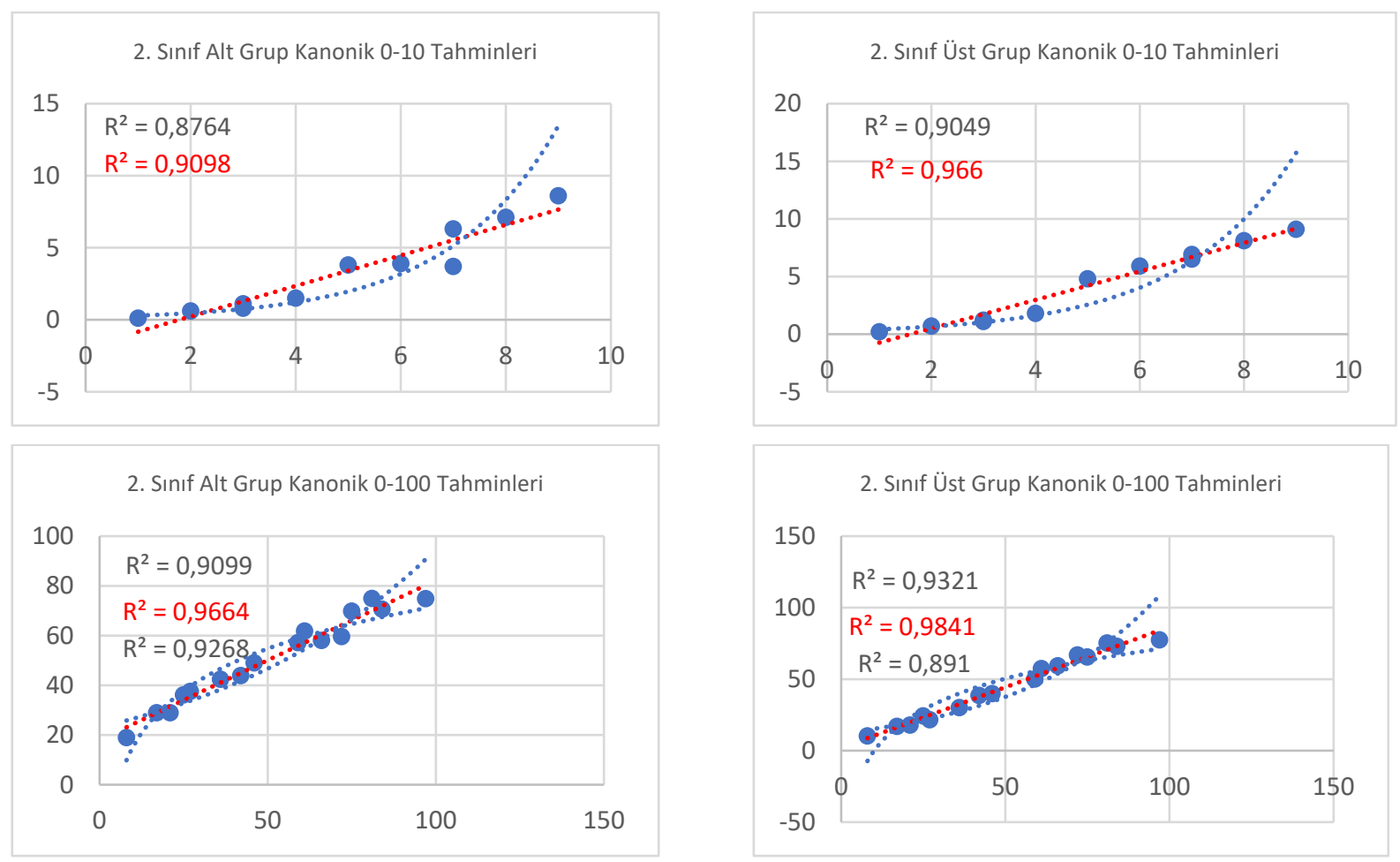

Şekil 8. İkinci sınıf alt ve üst grupların kanonik dizilmiş nokta 0-10 ve 0-100 tahmin karşılaştırılması 


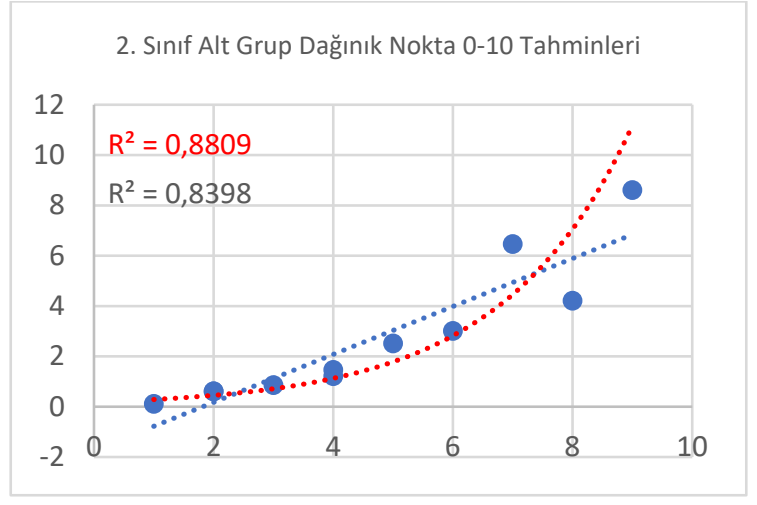

2. Sınıf Alt Grup Dağınık Nokta 0-100 Tahminleri

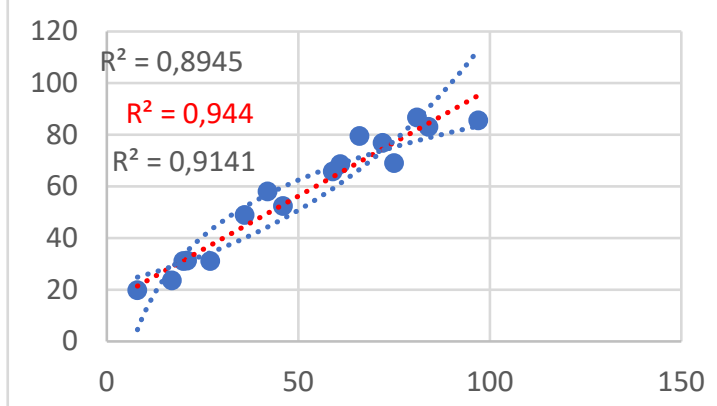

2. Sınıf Üst Gup Dağınık Nokta 0-10 Tahminleri

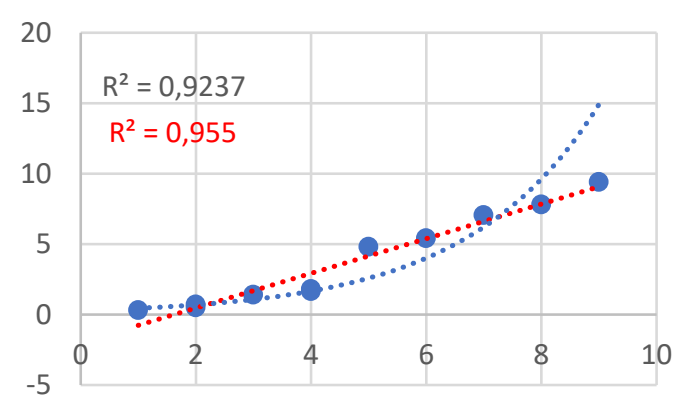

2. Sınıf Üst Grup Dağınık Nokta 0-100 Tahminleri

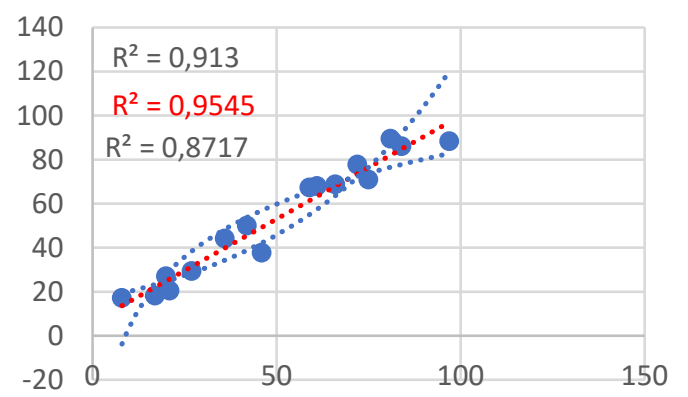

Şekil 9. İkinci sınıf alt ve üst grupların dağınık dizilmiş nokta 0-10 ve 0-100 tahmin karşılaştırılması
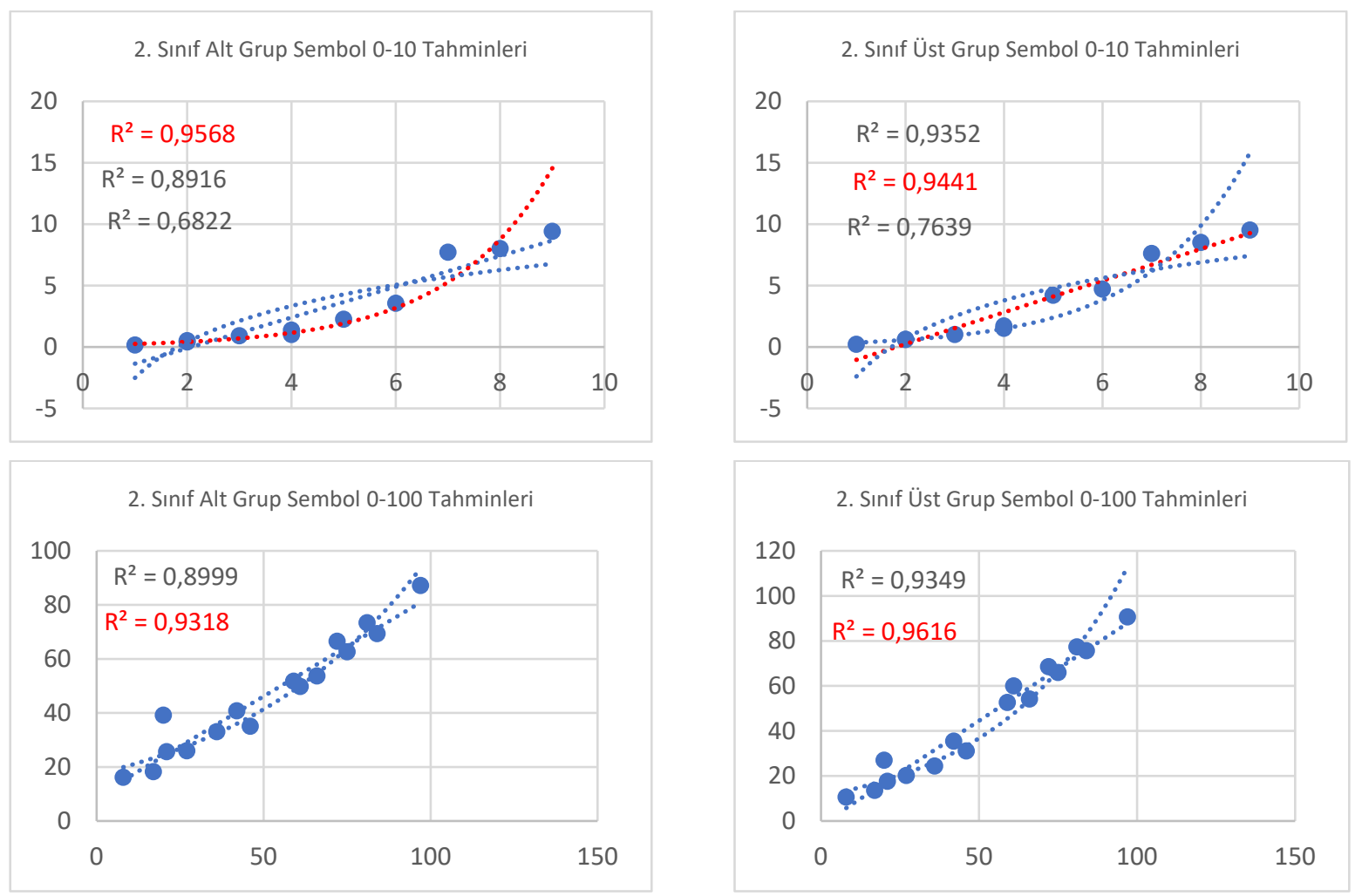

Şekil 10. İkinci sınıf alt ve üst grupların sembol 0-10 ve 0-100 tahmin karşılaştırılması 

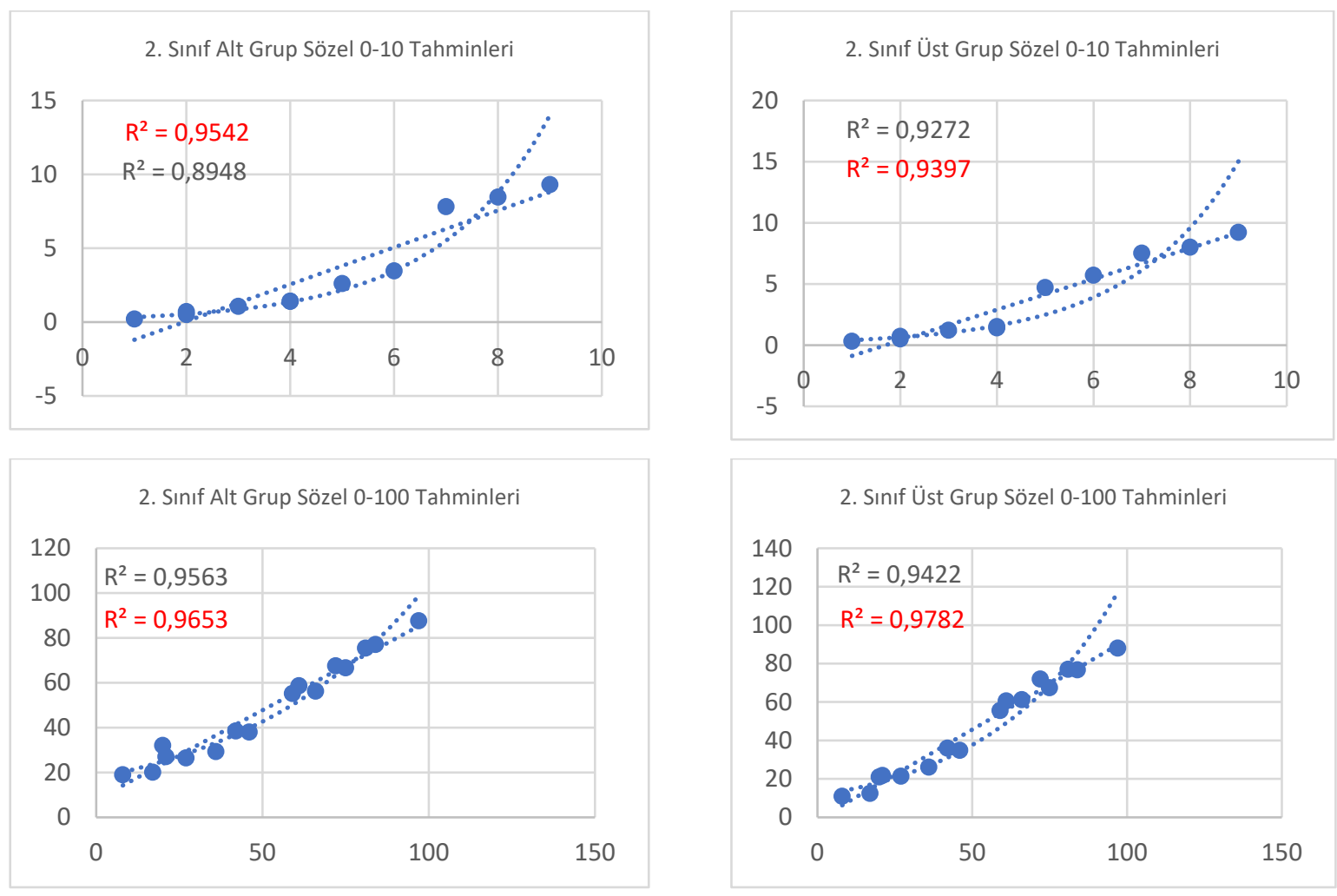

Şekil 11. İkinci sınıf alt ve üst grupların sözel 0-10 ve 0-100 tahmin karşılaştırılması

Üçlü kodlama modelinde yer alan sözel, analog ve sembolik temsil görevlerinin (Şekil 8-11) her birinde ikinci sınıf üst \%25'lik grupta yer alan öğrencilerin medyan sayı doğrusu tahminlerinin doğrusal regresyon çizgisine daha iyi uyduğu görülmektedir. Diğer bir ifadeyle üst grupta yer alan öğrencilerin sözel, analog ve sembolik temsil görevlerindeki tahmin becerilerinin alt \%25'lik grupta yer alan öğrencilerin tahmin becerilerine göre daha doğrusal (lineer) olduğu görülmektedir.

İkinci sınıf alt-üst grup karşılaştırmalarında olduğu gibi regresyon modeli kullanılarak üçüncü sınıf altüst \%25'lik grupların tahminlerinin uygunluğu karşılaştırılmıştır. Grupların sayı doğrusu tahminlerine ait medyan değerleri bulunarak R-kare değerleri hesaplanmıştır. Hesaplamalar sonucunda üçüncü sınıf alt-üst \%25’lik gruplardaki öğrencilere ait ortaya çıkan grafikler Şekil 12, Şekil 13, Şekil 14 ve Şekil 15'te verilmiştir.
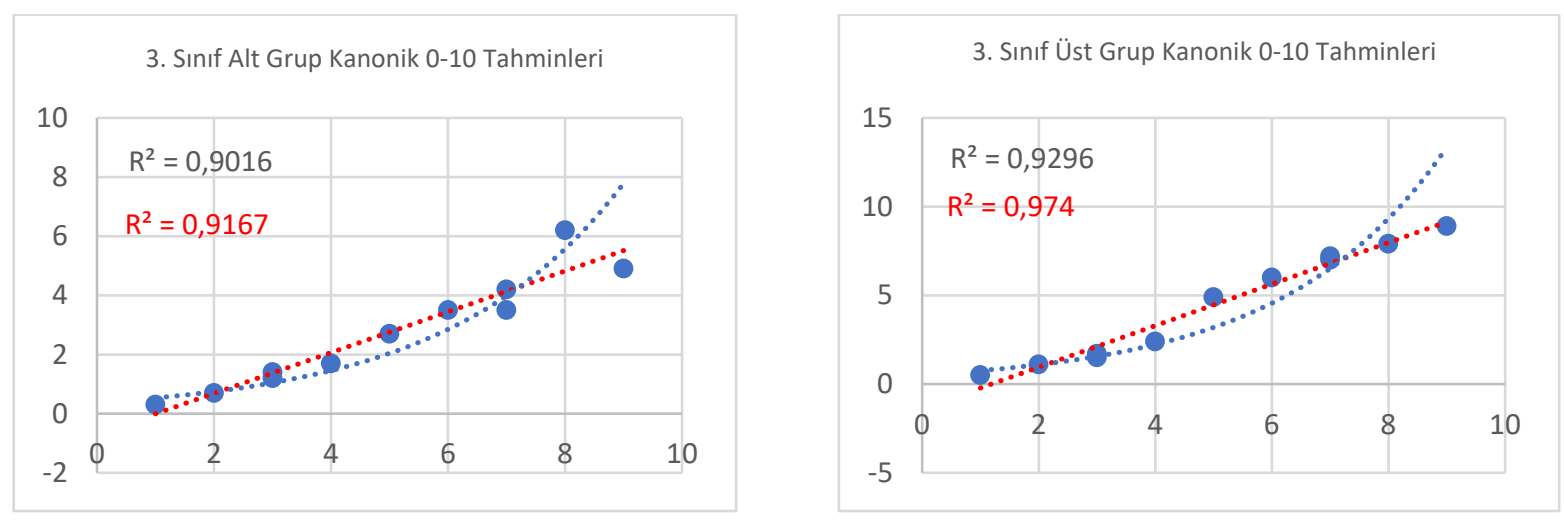

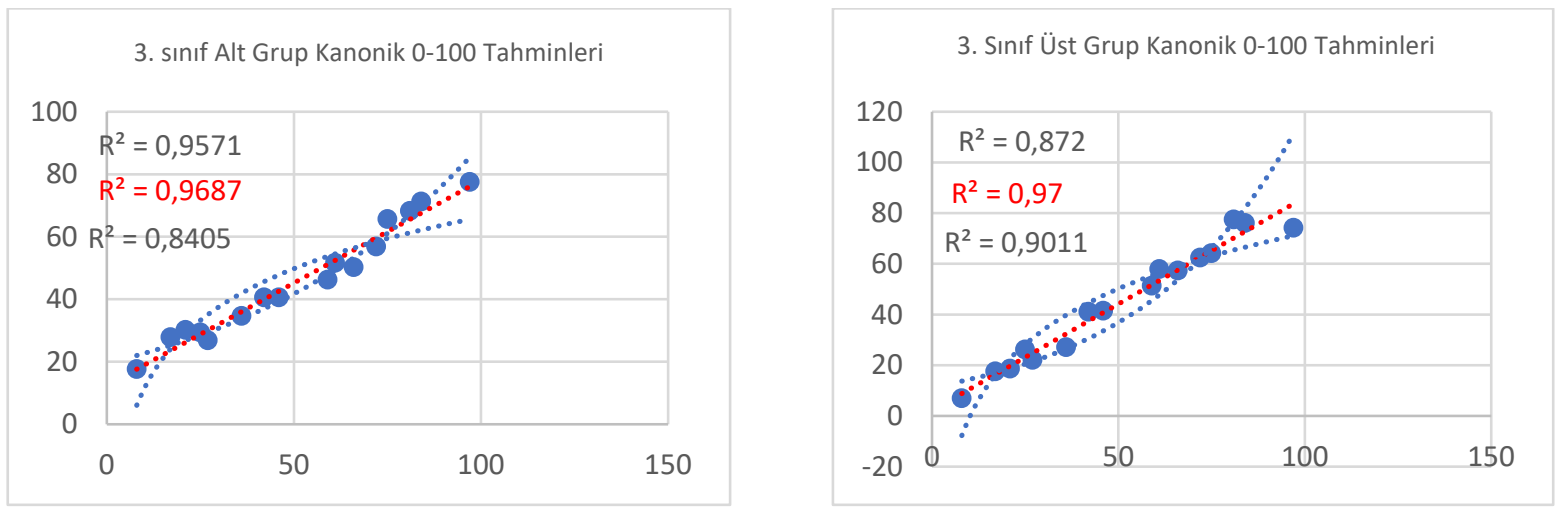

Şekil 12. Üçüncü sınıf alt ve üst grupların kanonik dizilmiş nokta 0-10 ve 0-100 tahmin karşılaştırılması
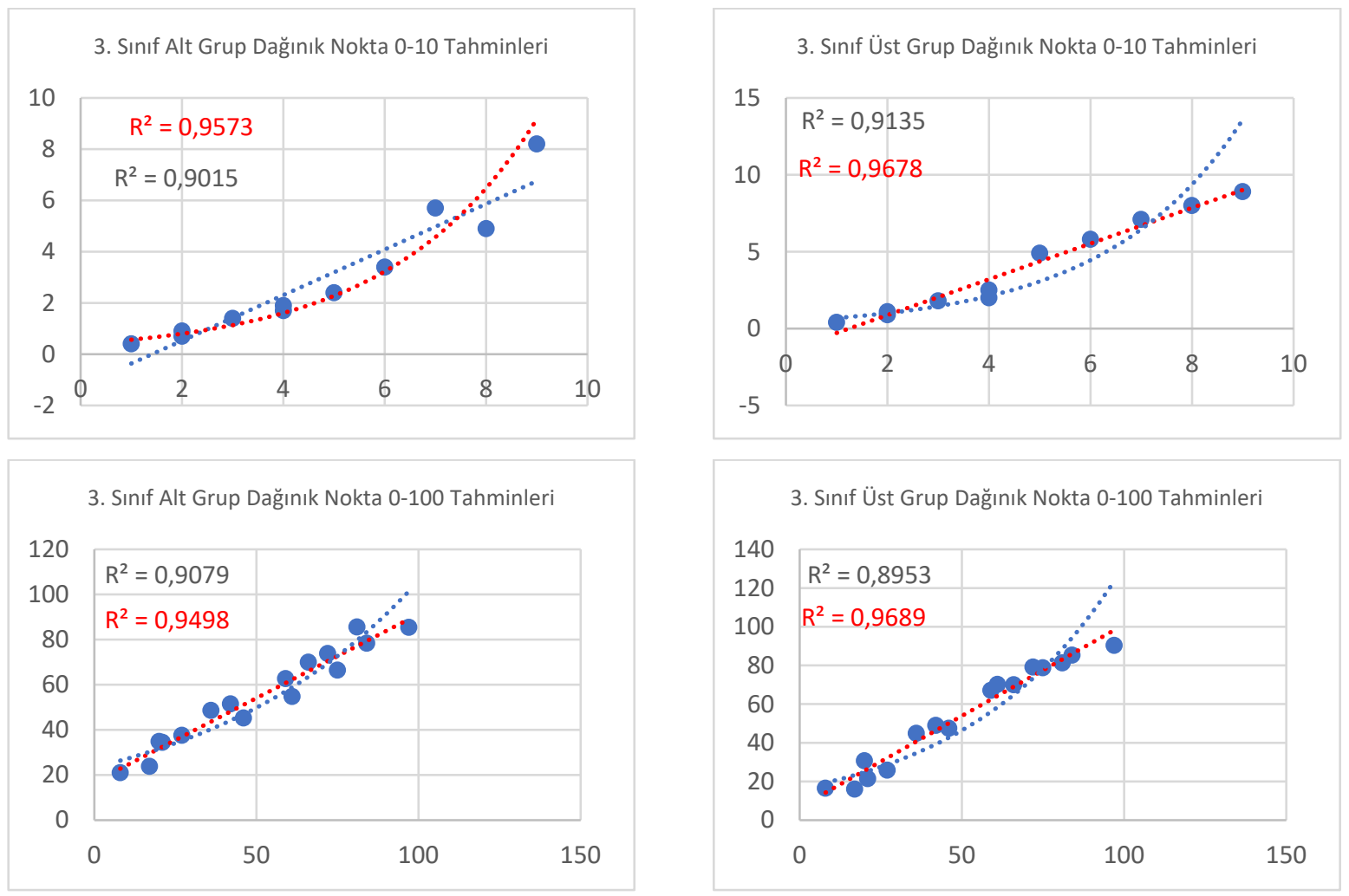

3. Sınıf Üst Grup Dağınık Nokta 0-100 Tahminleri

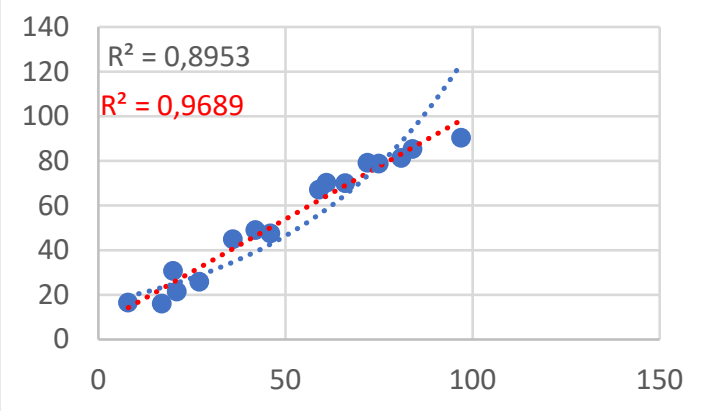

Şekil 13. Üçüncü sınıf alt ve üst grupların dağınık dizilmiş nokta 0-10 ve 0-100 tahmin karşılaştırılması
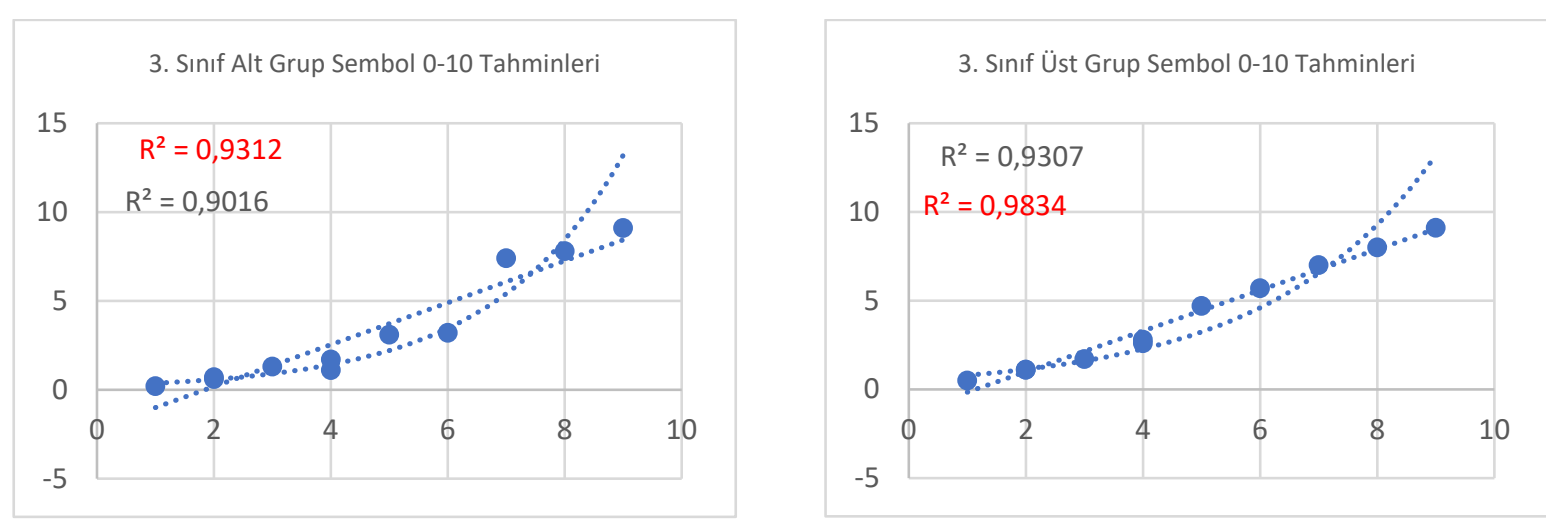

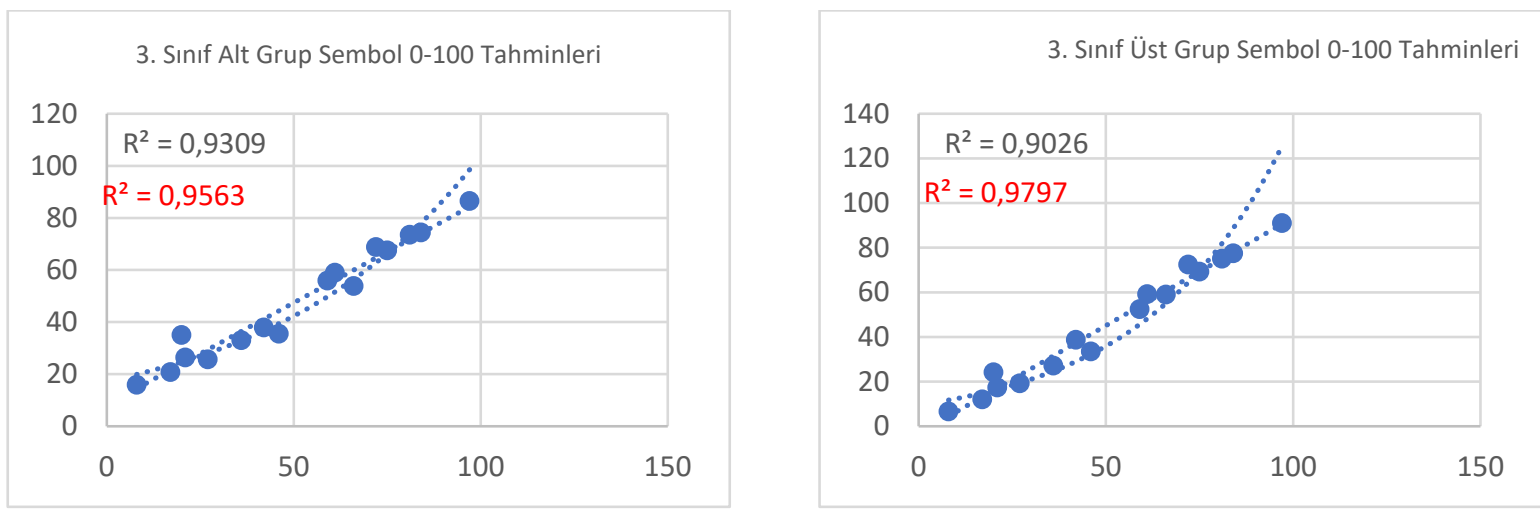

Şekil 14. Üçüncü sınıf alt ve üst grupların sembol 0-10 ve 0-100 tahmin karşılaştırılması
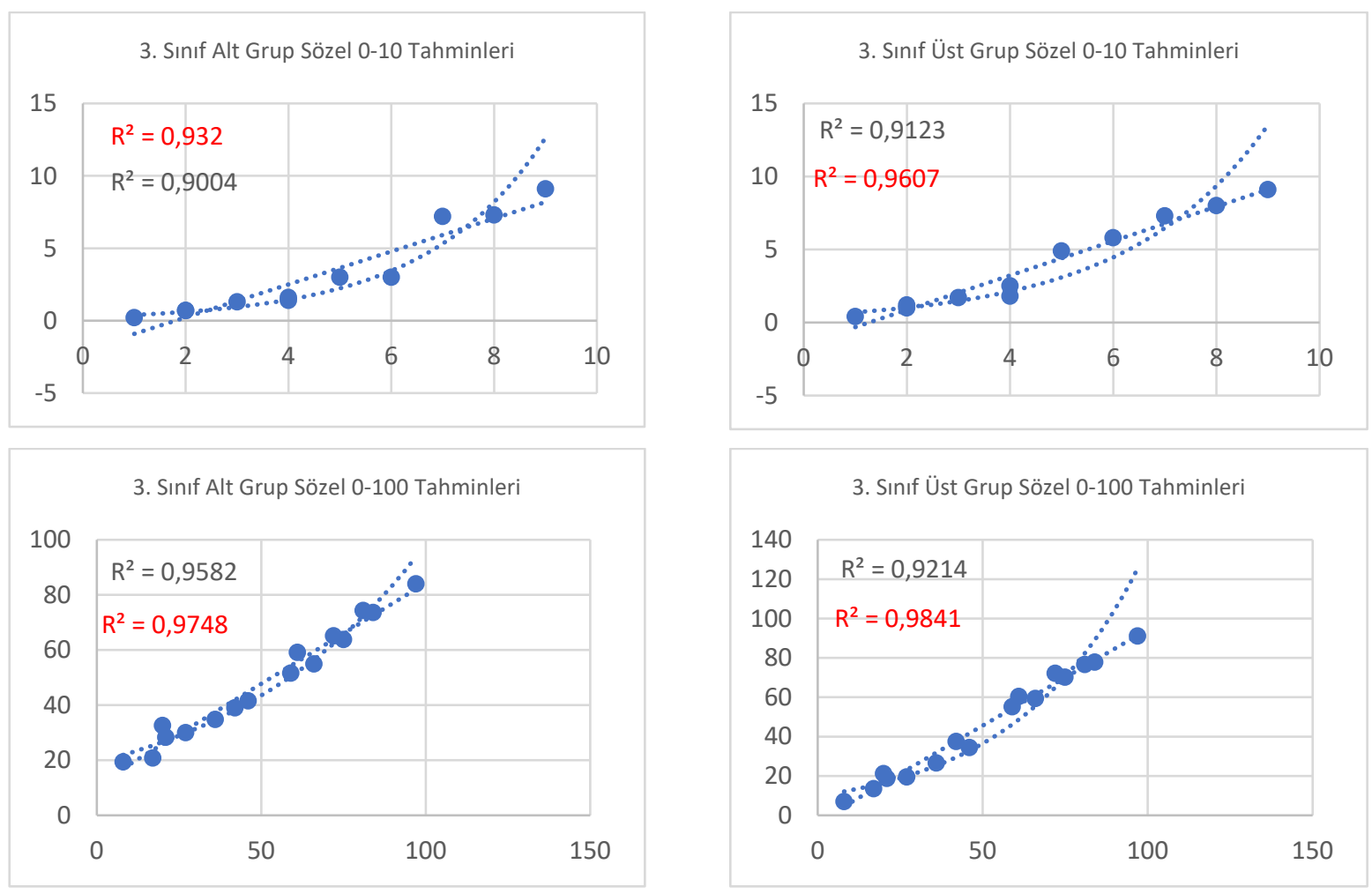

Şekil 15. Üçüncü sınıf alt ve üst grupların sözel 0-10 ve 0-100 tahmin karşlaştırılması

İkinci sınıflardan elde edilen bulgulara benzer şekilde sözel, analog ve sembolik temsil görevlerin (Şekil 12-15) her birinde üçüncü sınıf üst \%25'lik grupta yer alan öğrencilerin medyan sayı doğrusu tahminlerinin doğrusal regresyon çizgisine daha iyi uyduğu görülmektedir. Diğer bir ifadeyle üst grupta yer alan öğrencilerin sözel, analog ve sembolik temsil görevlerindeki tahmin becerilerinin alt \%25'lik grupta yer alan öğrencilerin tahmin becerilerine göre daha doğrusal (lineer) olduğu ortaya çıkmaktadır.

Araştırmada kullanılan testlerin birbirleri arasındaki korelasyon analizine ilişkin bulgular Tablo 4'te verilmiştir. 
Tablo 4. Araştırmada Kullanılan Testler Arasındaki Korelasyon Katsayılarına Ait Sonuçlar

\begin{tabular}{|c|c|c|c|c|c|c|c|c|c|c|c|}
\hline & MBT & $\mathrm{APT}$ & $\mathrm{BD}$ & $\begin{array}{c}\text { Sembol } \\
0-10 \\
\end{array}$ & $\begin{array}{c}\text { Sembol } \\
0-100 \\
\end{array}$ & $\begin{array}{c}\text { Sözel 0- } \\
10 \\
\end{array}$ & $\begin{array}{c}\text { Sözel 0- } \\
100 \\
\end{array}$ & $\begin{array}{c}\text { Rastgele } \\
0-10 \\
\end{array}$ & $\begin{array}{c}\text { Rastgele } \\
0-100 \\
\end{array}$ & $\begin{array}{c}\text { Kanonik } \\
0-10 \\
\end{array}$ & $\begin{array}{c}\text { Kanonik } \\
0-100 \\
\end{array}$ \\
\hline MBT & - &, $725^{* *}$ &, $580^{* *}$ &, $419^{* *}$ &, $305^{* *}$ &, $433^{* *}$ &, $287^{* *}$ &, $421^{* *}$ & , 220*** &, $415^{* *}$ &, $185^{* *}$ \\
\hline APT & & - &, $505^{* *}$ &, $167^{*}$ &, $224^{* *}$ & ,202** &, $167^{*}$ &, $203^{* *}$ & ,093 &, $256^{* *}$ &,- 030 \\
\hline $\mathrm{BD}$ & & & - &, $488^{* *}$ &, $428^{* *}$ &, $393^{* *}$ &, $412^{* *}$ &, $424^{* *}$ & ,300** &, $395^{* *}$ & ,308* \\
\hline $\begin{array}{c}\text { Sembol } \\
0-10 \\
\end{array}$ & & & & - & , 452 & $809^{* *}$ & $480^{* *}$ &, $754^{* *}$ &, $381^{* *}$ &, $715^{* *}$ &, $446^{* *}$ \\
\hline $\begin{array}{c}\text { Sembol } \\
0-100 \\
\end{array}$ & & & & & - & , 398** &, $741^{* *}$ &, $394^{* *}$ &, $384^{* *}$ & $355^{* *}$ &, $446^{* *}$ \\
\hline $\begin{array}{c}\text { Sözel 0- } \\
10 \\
\end{array}$ & & & & & & - & $430^{* *}$ &, $842^{* *}$ &, $333^{* *}$ &, $739^{* *}$ &, $385^{* *}$ \\
\hline $\begin{array}{c}\text { Sözel 0- } \\
100 \\
\end{array}$ & & & & & & & - &, $429^{* *}$ & ,499** &, $361^{* *}$ &, $556^{* *}$ \\
\hline $\begin{array}{c}\text { Rastgele } \\
0-10 \\
\end{array}$ & & & & & & & & - &, $325^{* *}$ &, $779^{* *}$ &, $356^{* *}$ \\
\hline $\begin{array}{c}\text { Rastgele } \\
0-100 \\
\end{array}$ & & & & & & & & & - &, $304^{* *}$ &, $552^{* *}$ \\
\hline $\begin{array}{c}\text { Kanonik } \\
0-10 \\
\end{array}$ & & & & & & & & & & - & ,342** \\
\hline $\begin{array}{c}\text { Kanonik } \\
0-100\end{array}$ & & & & & & & & & & & - \\
\hline
\end{tabular}

Testler arasındaki korelasyon katsayıları incelendiğinde (Tablo 4), en yüksek korelasyonun matematik başarısı (MBT) ile aritmetik performansıyla (APT) $(\mathrm{r}=.725 ; \mathrm{p}<.01)$ ve basamak değeri kavrayışı $(\mathrm{BD})(\mathrm{r}=.580$; $\mathrm{p}<.01)$ arasında olduğu görülmektedir. Aynı zamanda matematik başarısı Sembol 0-10 ( $r=.419 ; \mathrm{p}<.01)$, Sözel $0-10(\mathrm{r}=.433 ; \mathrm{p}<.01)$, Rastgele $0-10(\mathrm{r}=.421 ; \mathrm{p}<.01)$ ve Kanonik $0-10(\mathrm{r}=.415 ; \mathrm{p}<.01)$ arasında orta düzeyde ve anlamlı bir ilişkiye sahiptir. Aritmetik performansa bakıldığında ise, en yüksek düzeyde ilişkinin basamak değeri kavrayışı ile olduğu görülmektedir $(r=.505 ; \mathrm{p}<.01)$. Basamak değeri kavrayışı ise, üçlü kodlama modelindeki tüm testler orta düzeyde ve anlamlı bir ilişkiye sahiptir.

Sembol 0-10 testi, üçlü kodlama modelinde Sözel 0-10 (r= .809; $\mathrm{p}<.01)$, Kanonik noktalar sayma ( $\mathrm{r}=.754$; $\mathrm{p}<.01)$ ve Rastgele noktalar sayma $(\mathrm{r}=.715 ; \mathrm{p}<.01)$ ile yüksek düzeyde ve anlamlı bir ilişkinin varlı̆̆ görülmektedir. Benzer şekilde Sözel 0-10, Kanonik noktalar sayma ( $\mathrm{r}=.842 ; \mathrm{p}<.01)$ ve Rastgele noktalar sayma $(\mathrm{r}=.739 ; \mathrm{p}<.01)$ ile yüksek düzeyde ve anlamlı bir ilişkiye sahiptir. Rastgele 0-10 ile Kanonik noktalar sayma arasında $(\mathrm{r}=.779 ; \mathrm{p}<$.01) yüksek düzeyde ilişki görülmektedir. Üçlü kodlama modelindeki 0-100 testleri arasında ise genel olarak orta düzeyde ve anlamlı bir ilişki ortaya konulmuştur.

Araştırmada üçlü kod modelinden (0-10) hangi kod türlerinin çocukların matematik başarısı, aritmetik performansı ve basamak değeri kavrayışı en çok yordadığını ortaya koymak için yapılan çoklu doğrusal regresyon analizi (stepwise) sonuçları Tablo 5, Tablo 6 ve Tablo 7'de verilmiştir.

Tablo 5. Üçlü Kodlama Modeli 0-10 ile MBT Arasındaki Regresyon Analizi Sonucu

\begin{tabular}{clcccccc}
\hline Model & Değişkenler & $\mathrm{R}$ & $\mathrm{R}^{2}$ & $\mathrm{~F}$ & $\beta$ & $\mathrm{t}$ & $\mathrm{p}$ \\
\hline 1 & Sözel 0-10 & $.433(\mathrm{a})$ & .187 & 48.814 & 6.840 & 1.104 & .001 \\
2 & Sözel 0-10 & & & & & & .001 \\
& Kanonik 0-10 & $.455(\mathrm{~b})$ & .207 & 27.540 & 8.799 & 1.421 & .023 \\
\hline
\end{tabular}

a Yordayıcılar: (Constant), Sözel 0-10 b Yordayıcılar: (Constant), Sözel 0-10, Kanonik nokta sayma 0-10

Tablo 5 incelendiğinde, çocukların matematik başarılarını yordayan en önemli değişken Sözel 0-10'dur $\left(\mathrm{R}=.433, \mathrm{R}^{2}=.187\right)(\mathrm{F}(1,212)=48.814, \mathrm{p}<.01)$. Sözel 0-10 tek başına matematik başarısının \%19'unu açıklamaktadır. Sözel 0-10 ile birlikte Kanonik 0-10 bir araya geldiğinde matematik başarısının yaklaşık \%21'ini açıklamaktadır $\left(\mathrm{R}=.455, \mathrm{R}^{2}=.207\right)(\mathrm{F}(1,212)=27.540, \mathrm{p}<.01)$. 
Öğrencilerin Üçlü Kodlama Modelinde Sunulan Sayısal ...

Tablo 6. Üçlü Kodlama Modeli 0-10 ile BD Arasındaki Regresyon Analizi Sonucu

\begin{tabular}{cccccccc}
\hline Model & Değişkenler & $\mathrm{R}$ & $\mathrm{R}^{2}$ & $\mathrm{~F}$ & $\beta$ & $\mathrm{t}$ & $\mathrm{p}$ \\
\hline 1 & Sembol 0-10 & $.833(\mathrm{a})$ & .238 & 66.141 & 25.426 & 5.242 & .001
\end{tabular}

a Yordayıc1lar: (Constant), Sembol 0-10

Tablo 6 incelendiğinde, çocukların basamak değeri kavrayışını açıklayan en önemli değişken Sembol 0$10^{\prime}$ dur $\left(\mathrm{R}=.833, \mathrm{R}^{2}=.238\right)(\mathrm{F}(1,212)=66.141, \mathrm{p}<.01)$. Sembol 0-10 basamak değeri kavrayışının yaklaşık \%24'ünü açıklamaktadır.

Tablo 7. Üçlü Kodlama Modeli 0-10 ile APT Arasındaki Regresyon Analizi Sonucu

\begin{tabular}{cccccccc}
\hline Model & Değişkenler & $\mathrm{R}$ & $\mathrm{R} 2$ & $\mathrm{~F}$ & $\beta$ & $\mathrm{t}$ & $\mathrm{p}$ \\
\hline 1 & Kanonik 0-10 & $.256(\mathrm{a})$ & .065 & 14.833 & 34.628 & 7.507 & .001 \\
\hline
\end{tabular}

a Yordayıcılar: (Constant), Kanonik nokta sayma 0-10

Tablo 7 incelendiğinde, çocukların aritmetik performanslarını yordayan en önemli değişken Kanonik dizili noktalar $(0-10)^{\prime}$ dır $\left(\mathrm{R}=.256, \mathrm{R}^{2}=.065\right)(\mathrm{F}(1,212)=14.833, \mathrm{p}<.01)$. Kanonik 0-10 aritmetik performans becerisinin \%6'sını açıklamaktadır.

Araştırmada üçlü kod modelinden (0-100) hangi kod türlerinin çocukların matematik başarısı, aritmetik performansı ve basamak değeri kavrayışı en çok yordadığını ortaya koymak için yapılan çoklu doğrusal regresyon analizi (stepwise) sonuçları Tablo 9 ve Tablo 10' da verilmiştir.

Tablo 8. Üçlü Kodlama Modeli 0-100 ile MBT Arasındaki Regresyon Analizi Sonucu

\begin{tabular}{cccccccc}
\hline Model & Değişkenler & $\mathrm{R}$ & $\mathrm{R} \mathrm{R}^{2}$ & $\mathrm{~F}$ & $\beta$ & $\mathrm{t}$ & $\mathrm{p}$ \\
\hline 1 & Sembol 0-100 & $.305(\mathrm{a})$ & .093 & 21.978 & 1.385 & .134 & .001 \\
\hline
\end{tabular}

a Yordayıcilar: (Constant), Sembol 0-100

İlkokul 2. ve 3.sınıf öğrencilerinin matematik başarılarını üçlü kodlama modelinden en fazla yordayan değişken Sembol 0-100'dür $\left(\mathrm{R}=.305, \mathrm{R}^{2}=.093\right)(\mathrm{F}(1,212)=21.978, \mathrm{p}<.01)$. Sembol 0-100 matematik başarısının yaklaşık \%10'unu açıklamaktadır (Tablo 8 ).

Tablo 9. Üçlü Kodlama Modeli 0-100 ile APT Arasındaki Regresyon Analizi Sonucu

\begin{tabular}{cccccccc}
\hline Model & Değişkenler & $\mathrm{R}$ & $\mathrm{R}^{2}$ & $\mathrm{~F}$ & $\beta$ & $\mathrm{t}$ & $\mathrm{p}$ \\
\hline 1 & Sembol 0-100 & $.224(\mathrm{a})$ & .046 & 11.190 & 14.914 & 1.355 & .001 \\
2 & Sembol 0-100 & & & & & .001 \\
& Kanonik 0-100 & $.267(\mathrm{~b})$ & .063 & 4.815 & 22.883 & 1.990 & .029 \\
\hline
\end{tabular}

a Yordayıc1lar: (Constant), Sembol 0-100 b Yordayıcılar: (Constant), Sembol 0-100, Kanonik nokta sayma 0-100

Tablo 9 incelendiğinde, öğrencilerin aritmetik performanslarını yordayan üçlü kodlama modelindeki en önemli değişken Sembol 0-100' dür $\left(\mathrm{R}=.224, \mathrm{R}^{2}=.046\right)(\mathrm{F}(1,212)=11.190, \mathrm{p}<.01)$. Sembol 0-100 tek başına aritmetik performanstaki başarının yaklaşık \%5'ini açılamaktadır. Sembol 0-100 ile birlikte Kanonik 0-100 bir araya geldiğinde aritmetik performansının \% 6'sı açıklanmaktadır $\left(\mathrm{R}=.267, \mathrm{R}^{2}=.063\right)(\mathrm{F}(1,212)=4.815, \mathrm{p}<.01)$. 
Tablo 10. Üçlü Kodlama Modeli 0-100 ile BD Arasındaki Regresyon Analizi Sonucu

\begin{tabular}{|c|c|c|c|c|c|c|c|}
\hline Model & Değişkenler & $\mathrm{R}$ & $\mathrm{R}^{2}$ & $\mathrm{~F}$ & $\beta$ & $t$ & $\mathrm{p}$ \\
\hline 1 & Sembol 0-100 & $.428(a)$ & .179 & 47.422 & 5.306 & .619 & .001 \\
\hline & Sembol 0-100 & & & & & & .001 \\
\hline 2 & $\begin{array}{l}\text { Rastgele noktalar } \\
0-100\end{array}$ & $.452(b)$ & .197 & 5.727 & -2.508 & -.312 & .018 \\
\hline
\end{tabular}

a Yordayıc1lar: (Constant), Sembol 0-100 b Yordayıcılar: (Constant), Sembol 0-100, Rastgele Noktalar Counting 0-100

Son olarak ilkokul 2. ve 3.sınıf öğrencilerinin basamak değeri kavrayışlarını üçlü kodlama modelinden en fazla yordayan değişken Sembol 0-100'dür $\left(\mathrm{R}=.428, \mathrm{R}^{2}=.179\right)(\mathrm{F}(1,212)=47.422$, $\mathrm{p}<.01)$. Sembol 0-100 tek başına basamak değeri kavrayışının yaklaşık \%18'ini açıklamaktadır (Tablo 10). Sembol 0-100 ile birlikte Rastgele noktalar sayma 0-100 bir araya geldiğinde basamak değeri kavrayışının yaklaşık \% 20'si açıklanmaktadır $(\mathrm{R}=$ $\left..452, \mathrm{R}^{2}=.197\right)(\mathrm{F}(1,212)=-2.508, \mathrm{p}<.01)$

\section{Sonuç ve Tartışma}

Matematiksel bilişteki gelişimsel değişimler hakkındaki anlayışımız son 40 yıl içinde önemli ölçüde ilerlemiştir. Formal matematik öğrenimini sağlayan okul çağındaki çocukların ve yetişkinlerin yanı sıra sözel öncesi dönem bebekleri, küçük çocuklar ve okul öncesi çocukların sezgisel sayı hissini incelemek için çeşitli yenilikçi görevler kullanılmaktadır (Berch ve diğerleri, 2016). Bu yenilikçi görevler arasında yer alan araçlardan biri de üçlü kodlama modelidir. Araştırmada ilkokul ikinci ve üçüncü sınıf öğrencilerinin üçlü kodlama modeline (sembolik, sözel ve analog) göre tasarlanan sayı doğrusu tahmin görevlerindeki becerilerinin matematik başarıları, aritmetik performansları ve basamak değeri kavrayışları arasındaki ilişkisi ortaya konulmuştur.

Araştırmadan elde edilen bulgulardan ilki, üçüncü sınıf öğrencilerinin sayı doğrusu üzerinde tüm testlerde ((sözel, sembolik ve analog) tahmin becerileri ikinci sınıf öğrencilerine göre daha doğrusaldır. Sınıf seviyelerine göre yapılan karşılaştırmalarda üçüncü sınıflar ikinci sınıflara göre sayının bütün temsilleri (sözel, sembolik ve analog) ile yapılan tahminlerde daha başarılı bir performans sergilemişlerdir. Benzer bir durum aynı sınıf düzeyinde alt ve üst başarı grupları arasında yapılan karşılaştırmalarda da ortaya çıkmıştır. Alt ve üst grupta yer alan öğrencilerin başarısı APT, BD, SDT 0-10 ve 0-100 açısından farklılaşmaktadır. Bu farklılaşmanın özellikle APT ve BD testleri açısından daha belirgin olduğu görülmüştür. Sınıf seviyesi arttıkça alt ve üst gruplar arasındaki başarı farkı daha da açılmaktadır.

Elde edilen bu bulgular sayı büyüklüğünün temsil şekillerinin yaş, eğitim ve deneyimle birlikte gelişerek logaritmik durumdan doğrusal (lineer) bir şekle dönüştüğü görüşünü desteklemektedir (Booth ve Siegler, 2006; Siegler ve Booth, 2004; Siegler ve Opfer, 2003; Olkun, Sar1 ve Smith, 2019; Sar1 ve Olkun, 2018; Sar1 ve Olkun, 2021; Olkun, Mutlu ve Sarı, 2017). Örneğin, Siegler ve Booth (2004) tarafından yapılan araştırmada okul öncesi, birinci sınıf ve ikinci öğrencilerinin sayı doğrusunda (0-100) tahmin becerilerinin okul öncesi çocuklarda logaritmik, birinci sınıfta logaritmik ve doğrusal ve ikinci sınıfta ise doğrusal olduğu ortaya konulmuştur. Benzer şekilde Geary ve diğerleri (2008) birinci ve ikinci sinıfta matematik öğrenme güçlüğü yaşayan öğrencilerin daha çok logaritmik; tipik başarıya sahip olan öğrencilerin daha çok lineer temsil kullandıklarını ortaya koymuşlardır (Geary ve diğerleri, 2008). Landerl (2013) ise, ikinci sınıftan dördüncü sınıfa kadar diskalkuliye sahip öğrencilerle yaşıtlarının (0-100 ve 0-1000) sayı doğrularındaki tahminlerini incelendiği araştırmada diskalkuliye sahip öğrencilerin tahminlerinin yaşıtlarından daha hatalı olduğu bulunmuştur. Öğrencilerin tahmin becerilerinde yaş arttıkça bir gelişme olmasına karşın diskalkuliye sahip öğrencilerin yaşıtları ile aralarındaki tahmin becerilerindeki farklar korunmuştur.

Tüm bu araştırma bulguları birlikte ele alındığında yaş, deneyim ve eğitimle birlikte gelişen sayı doğrusu tahmin becerileri özellikle düşük başarılı öğrenciler ile normal başarı gösteren öğrenciler arasında anlamlı düzeyde farklılaşmaya devam ettiğini göstermektedir. Sayının farklı temsilleri (sözel, sembolik ve analog) ile 
yapılan tahmin becerilerinin aritmetik performansı, basamak değeri kavrayışını ve genel olarak matematik başarısını da yordadığı bulgusu birlikte ele alındığında düşük başarılı öğrencilerin sayının çok yönlü algılanması ile ilgili genel bir yetersizliklerinin olduğu ileri sürülebilir. Bu genel yetersizlikler alanyazında çekirdek yetmezliği hipotezi ve erişim eksikliği hipotezi ile açıklanmaktadır (Gilmore, McCarthy ve Spelke, 2010; Landerl, Bevan ve Butterworth, 2004; Rousselle ve Noel, 2007; Sasanguie vd., 2013). Çekirdek yetmezliği hipotezi içinde yaklaşık sayı sistemine (YSS) ve tam sayı sistemine (TSS) ait sayısal görevler yer almaktadır (Dehaene, 2003; Landerl ve diğerleri, 2004; Wilson ve Dehaene, 2007). Mevcut araştırmada kullanılan YSS ve TSS testlerinde alt grupta yer alan öğrencilerin düşük performans sergilemelerinden dolayı bu çocukların matematik bozukluğu riskli oldukları söylenebilir. Benzer şekilde erişim eksikliği hipotezi içinde sembolden temsil ettiği çokluğa ya da çokluktan sembolik temsile (SES) ait görevler vardır. Araştırmada alt grup öğrencilerinin SES testlerinde düşük performans sergilemeleri bu çocukların matematik bozukluğu riskli olduklarının bir kanıtı olabilir. Çünkü matematikte yaşanan güçlüğün nedenleri arasında semboller ve bu sembollerin eşleştiği büyüklük arasındaki bir gecikmeden kaynaklanabileceği başka bir deyişle erişim eksikliği olabileceği ifade edilmektedir (Gilmore ve diğerleri, 2010; Olkun ve Akkurt-Denizli, 2015; Sasanguie vd., 2013). Araştırmada ikinci sınıflarda düşük başarılı ve yüksek başarılı öğrencilerin karşılaştırılmasında yüksek başarılı öğrencilerin de sembol ve sözel temsillerde diğer temsillere göre küçük sayı ve büyük sayı tahminleri arasındaki farkların büyük olması ve yine 2.sınıfların sayısal büyüklükleri sembole ve sözel temsile dönüştürme konusunda zorluk yaşamalarına yönelik alanyazın bulgularını güçlendirmektedir.

Araştırmadan elde edilen diğer bulgular ise, üçlü kod modeline göre tasarlanan 0-10 tahmin aralığındaki testlerden Sözel 0-10 ve Kanonik 0-10 matematik başarısını daha çok yordamaktadır. Basamak değeri kavrayışını en çok Sembol 0-10 yordarken, aritmetik performansını en çok Kanonik nokta sayılama 0-10 yordamaktadır. 0-100 aralığında tahmin testlerine bakıldığında ise, matematik başarısını en çok Sembol 0-100 yordarken, basamak değeri kavrayışını da Sembol 0-100 ve Rastgele nokta sayılama yordamaktadır. Öğrencilerin aritmetik performanlarını 0-100 aralığındaki sayı doğrusu testlerinden Sembol (0-100) ve Kanonik (0-100) değişkenleri yordamaktadır. Bu bulgular birlikte ele alındığında üçlü kodlama modelinde yer alan Sembolik, Analog ve Sözel temsillerin her birinin bir iskeleye temel sağladığı ifade edilebilir. Çünkü sembolik sayısal büyüklük işlemenin, çocukların erken aritmetik gerçekleri ediniminde, bireysel farklılıklarda ve gelişimsel değişikliklerde benzersiz bir rol oynayabileceğini ve yetkin sembolik büyüklük işlemenin, aritmetik gerçekleri geliştirmek için önemli bir iskele sağladığı belirtilmektedir (De Smedt, 2016). Benzer şekilde analog büyüklük kodu, yaklaşık hesaplama, tahmin ve sayı büyüklükleri karşılaştırmalarını desteklerken, şipşak sayılamada da önemli bir role sahiptir. Çok basamaklı işlemlere ise rakamsal sayı formları aracılık etmektedir (Campbell ve Epp, 2005). Tam sayı sistemi içerisinde yer alan temsiller kusursuz aritmetik becerisini gerçekleştirmemize ve hatta trigonometri, cebir ve kalkülüs gibi daha karmaşık matematik öğrenmemize izin vermektedir (Libertus, 2019). Bu nedenle farklı temsil biçimlerinin ve sayısal büyüklüklerin tahmin edilmesinin, basamak değeri ve aritmetik performans gibi farklı matematik becerilerini etkilediği söylenebilir. Bu da farklı temsil biçimleri kullanılarak yapılacak tahmin çalışmalarının çocukların daha derin ve kapsamlı bir matematik kavrayışı açısından daha yararlı olacağı sonucuna varılabilir.

Son olarak grafik görsellerin ayrıntılı incelemesinden de görüleceği gibi yüksek başarılı öğrencilerin sayının büyüklügünden daha az etkilendikleri öte yandan düşük başarılı öğrencilerin ise farklı sayısal büyüklük aralıklarında daha inişli çıkışlı bir performans gösterdikleri görülmektedir. Düşük ve yüksek başarılı öğrencileri arasındaki farklar özellikle aritmetik performans, basamak değeri kavrayışı ve küçük sayıların (sıfır on arası) göreceli büyüklüklerinin tahmin edilmesinde daha da artmaktadır. Küçük sayıların tahminlerinde daha kötü bir performans sergilenmesi beklenmedik bir bulgu olsa da bunun nedeninin tahminde strateji kullanımlarından kaynaklanabileceği düşünülmektedir. Ayrıca küçük sayılarda yapılan tahminlerin hem düşük hem de yüksek başarılı öğrencilerde büyük sayılara göre daha hatalı olması bu görüşü desteklemektedir. Hata miktarı açısından ise düşük başarılı öğrencilerin hata açıklığı daha fazladır. Olkun ve arkadaşları (2015) tarafından yapılan bir araştırmada Matematik öğrenme güçlüğü (MÖG) risk grubunda olan birinci ve ikinci sınıf öğrencileri sembolik sayı karşılaştırma (SSK) görevlerinde de düşük yeterlikler sergilemişlerdir. Söz konusu araştırmada birinci sınıfta, Kanonik Nokta Sayılama (KNS), Sembolik Sayı karşılaştırma (SSK) ve Zihinsel Sayı Doğrusunda tahmin (ZSD) görevlerinin matematik başarısını yordamada 
güçlü olduğu, bunlardan da KNS'nın en güçlü yordayıcı olduğu görülmüştür. İkinci sınıfta, KNS ve SSK görevlerinin matematik başarısını yordamada güçlü olduğu, bunlardan da KNS'nin yine en güçlü yordayıcı olduğu görülmüştür. Üçüncü sınıfta, yalnızca KNS ve ZSD görevlerinin matematik başarısını yordamada güçlü olduğu, bunlardan da yine KNS'nin en güçlü yordayıcı değere sahip olduğu görülmüştür. Dördüncü sınıfta, KNS ve ZSD görevlerinin matematik başarısını yordamada güçlü olduğu, bunlardan da ZSD'nun en güçlü yordayıcı olduğu görülmüştür (Olkun ve diğerleri, 2015).

Sonuç olarak bulguların, farklı formatlarda sunulan sayı algılarının çocuklarda farklı performanslara neden olabileceği görüşünü desteklediği söylenebilir. Bu nedenle pedagojik olarak farklı temsil biçimleriyle yapılacak öğretimin çocukların matematiği derinlemesine anlamaları için daha faydalı olacağı sonucuna varılabilir.

\section{Yazarların Beyanı}

Araştırmacıların katkı oranı beyanı: Araştırmacılarından MHS ve SO makalenin tüm yazım sürecine eşit katkıda bulunmuşlardır.

Etik Kurul Kararı: Nevşehir HBV Üniversitesi 23.06.2020 tarih ve 13 nolu toplantı uygunluk kararı.

Çatışma beyanı: Yazarlar arasında herhangi çıkar çatışması bulunmamaktadır.

\section{Kaynaklar}

Ansari, D. (2010). Neurocognitive approaches to developmental disorders of numerical and mathematical cognition: The perils of neglecting the role of development. Learning and Individual Differences, 20(2), 123129.

Berch, D. B., Geary, D. C., \& Koepke, K. M. (2016). Introduction: How the study of neurobiological and genetic factors can enhance our understanding of mathematical cognitive development. D. B. Berch, D. C. Geary, \& K. M. Koepke (Ed.), Development of mathematical cognition: Neural substrates and genetic influences (Volume 2) (s. 1-24) içinde. San Diego: Academic Press.

Berteletti, I., \& Booth, J. R. (2016). Finger representation and finger-based strategies in the acquisition of number meaning and arithmetic. D. B. Berch, D. C. Geary, \& K. M. Koepke (Ed.), Development of mathematical cognition: Neural substrates and genetic influences (Volume 2) (s. 109-139) içinde. San Diego: Academic Press.

Booth, J. L., \& Siegler, R. S. (2006). Developmental and individual differences in pure numerical estimation. Developmental Psychology, 42(1), 189-201.

Campbell, J. I., \& Epp, L. J. (2005). Architectures for arithmetic. J. I. D. Campbell (Ed.), Handbook of mathematical cognition içinde (s. 347-360). Taylor \& Francis, Inc.

Canto-López, M. C., Aguilar, M., García-Sedeño, M. A., Navarro, J. I., Aragón, E., Delgado, C., \& Mera, C. (2021). Numerical estimation and mathematical learning methodology in preschoolers. Psychological Reports, 124(2), 438-458.

Dehaene, S. (2003). The neural basis of the weber-feschner law: A logarithmic mental number line. Trends in Cognitive Sciences, 7(4), 145-147.

Dehaene, S. (1992). Varieties of numerical abilities. Cognition, 44(1-2), 1-42.

De Smedt, B. (2016). Individual differences in arithmetic fact retrieval. In D. B. Berch, D. C. Geary, \& K. M. Koepke (Ed.), Development of mathematical cognition: Neural substrates and genetic influences (Volume 2) (s. 219-243) içinde. San Diego: Academic Press.

Fayol, M., \& Seron, X. (2005). About numerical representations: Insights from neuropsychological, experimental, and developmental studies. J. I. D. Campbell (Ed.), Handbook of mathematical cognition (s. 322) içinde. Taylor \& Francis, Inc. 
Fidan, E. (2013). Illkokul öğrencileri için matematik dersi sayılar öğrenme alanında başarı testi geliştirilmesi. (Yayımlanmamış Yüksek Lisans Tezi), Ankara Üniversitesi, Ankara.

Geary, D. C., Hoard, M. K., Nugent, L., \& Byrd-Craven, J. (2008). Development of number line representations in children with mathematical learning disability. Developmental Neuropsychology, 33(3), 277-299.

Geary, D. C., Hoard, M. K., Byrd-Craven, J., Nugent, L., \& Numtee, C. (2007). Cognitive mechanisms underlying achievement deficits in children with mathematical learning disability. Child development, 78(4), 1343-1359.

Gilmore, C. K., McCarthy, S. E., \& Spelke, E. S. (2010). Non-symbolic arithmetic abilities and mathematics achievement in the first year of formal schooling. Cognition, 115(3), 394-406.

Herzog, M., Fritz, A., \& Ehlert, A. (2017). Entwicklung eines tragfähigen Stellenwertverständnisses [Development of a resilient place value understanding]. A. Fritz and S. Schmidt (Ed.), Handbuch rechenschwäche içinde (s. 266-286). Basel: Beltz.

Landerl, K., Bevan, A., and Butterworth, B. (2004). Developmental dyscalculia and basic numerical capacities: a study of 8-9-year-old students. Cognition, 93(2), 99-125.

Landerl, K. (2013). Development of numerical processing in children with typical and dyscalculic arithmetic skills-a longitudinal study. Frontiers in Psychology, 4, 459.

Landerl, K. (2019). Neurocognitive perspective on numerical development. A. Fritz, V. G. Hasse, \& P. Rasanen (Ed.), International handbook of mathematical learning difficulties (s. 9-24) içinde. Cham: Springer,

Libertus, M. E. (2019). Understanding the link between the approximate number system and math abilities. D. C. Geary, D. B. Berch, \& K. Mann Koepke (Ed.), Cognitive foundations for improving mathematical learning (Vol. 5), içinde (s. 91-106): Academic Press.

Looi, C. Y., Thompson, J., Krause, B., \& Cohen Kadosh, R. (2016). The neuroscience of mathematical cognition and learning. OECD Education Working Paper No. 136. Erişim adresi: http://disde.minedu.gob.pe/bitstream/handle/123456789/4665/The\%20Neuroscience\%20of\%20Mathemati cal\%20Cognition\%20and\%20Learning.pdf?sequence $=1 \&$ isAlAlted $=y$

Long, I. S. A. (2019). Cognitive factors predicting variation in arithmetic performance (Doctoral dissertation). UK: University College London

Mutlu, Y., \& Sarı, M.H. (2019). İlkokul öğrencilerinin basamak değeri kavrayışlarının geliştirilmesi. Kastamonu Education Journal, 27(2), 657667.

Olkun, S. Can, D., \& Yeşilpınar, M. (2013). Hesaplama performansı testi: geçerlilik ve güvenilirlik çalışması. XII. Ulusal Sınıf Öğretmenliği Eğitimi Sempozyumunda tam metin kitabı. Aydın: Adnan Menderes Üniversitesi. ss.89-92.

Olkun, S., \& Akkurt-Denizli, Z. (2015). Using basic number processing tasks in determining students with mathematics disorder risk. Dusunen Adam: The Journal of Psychiatry and Neurological Sciences, 28, 47-57.

Olkun, S., Altun, A., Göçer Şahin, S., \& Akkurt-Denizli, Z. (2015). Deficits in basic number competencies may cause low numeracy in primary school children. Education and Science, 40(177), 141-159.

Olkun, S., Mutlu, Y., \& Sarl, M.H. (2017). The relationships between number sense and mathematics achievement. International Conference on Education and New Developments 2017, June 24-26, Lisbon, Portugal

Olkun, S., Sarı, M.H., \& Smith, G.G. (2019). Geometric aspects of number line estimations. Journal of Education and Future, 15, 37-46.

Paydar, S., \& Sarı, M.H. (2019). İlkokul ikinci ve üçüncü sınıf öğrencilerinin basamak değeri kavrayışları (S.Olkun ve diğerleri, Ed.), İlköğretim çalışmaları bütünsel açıdan çocuk içinde (s. 97-116). Ankara: Pegem Akademi Yayıncilık. 
Peters, L., De Smedt, B., \& Op de Beeck, H. (2015). The neural representation of Arabic digits in visual cortex. Frontiers in Human Neuroscience, 9, 1-12.

Peters, L., Polspoel, B., de Beeck, H. O., \& De Smedt, B. (2016). Brain activity during arithmetic in sembolic and non-sembolic formats in 9-12 year old children. Neuropsychologia, 86, 19-28.

Raven, J., Raven, J.C., \& Court, J.H. (2000, updated 2004). Manual for Raven's Progressive Matrices and Vocabulary Scales. Section 3: The Standard Progressive Matrices.

Rousselle, L., \& Noel, M. P. (2007). Basic numerical skills in children with mathematics learning disabilities: a comparison of symbolic vs non-symbolic number magnitude processing. Cognition, 102(3), 361-395.

Sarı, M.H., \& Olkun, S. (2018). The relationships among number line estimations, mathematics achievement and place value concept. An International Conference on Education, Technology and Science 2018, May 6-9, Belgrade, Serbia.

Sarı, M.H., \& Olkun, S. (2019). Relationship between place value understanding, arithmetic performance and mathematics achievement in general. İlköğretim Online, 18(2), 953-958.

Sarı, M. H., \& Olkun, S. (2021). The relationships among number line estimations, mathematics achievement and place value understanding. Journal of Education and Future, 19, 37-47.

Sari, M.H., Herzog, M., Olkun, S., \& Fritz-Stratmann, A. (t.y). Validation of a model of sustainable place value understanding in Turkey. [Araştırma bir dergide değerlendirme sürecindedir]

Sasanguie, D., Gobel, S. M., Moll, K., Smets, K., \& Reynvoet, B. (2013). Approximate number sense, symbolic number processing, or number-space mappings: what underlies mathematics achievement? Journal of Experimental Child Psychology, 114(3), 418-431.

Siegler, R. S., \& Booth, J. (2004). Development of numerical estimation in young children. Child Development, $75,428-444$.

Siegler, R. S., \& Opfer, J. E. (2003). The development of numerical estimation: evidence for multiple representations of numerical quantity. Psychological Science, 14(3), 237-250.

Skagenholt, M., Träff, U., Västfjäll, D., \& Skagerlund, K. (2018). Examining the triple code model in numerical cognition: An fMRI study. PLoS ONE, 13(6), 1-35.

Soares, N., Evans, T., \& Patel, D. R. (2018). Specific learning disability in mathematics: a comprehensive review. Translational Pediatrics, 7(1), 48-62.

Wilson, A. J., \& Dehaene, S. (2007). Number sense and developmental dyscalculia. In D. Coch, G. Dawson ve K. Fischer (Eds.), Human behavior, learning, and the developing brain: Atypical development (pp. 212-238). New York: Guilford Press.

Wu, S. S., Willcutt, E. G., Escovar, E., \& Menon, V. (2014). Mathematics Achievement and Anxiety and Their Relation to Internalizing and Externalizing Behaviors. Journal of Learning Disabilities, 47(6), 503-514. 


\section{EXTENDED ABSTRACT}

\section{Introduction}

In mathematical cognitive development, besides general domain processes (e.g. working memory, processing speed), such basic skills as comparison of non-symbolic (e.g. random dots) and symbolic quantities (e.g. numbers), counting, and transcoding (i.e. converting from one numerical representation to another) form the bases for secondary mathematical skills such as the development of single-digit arithmetic and multi-step arithmetic operations; the place value understanding; conceptual and procedural knowledge of fractions; proportional reasoning; and equivalence (Berch ve diğerleri, 2016). In these processes, early arithmetic skills require children to understand the verbal counting sequence, the order in which the numbers appear, and the associated quantities or sizes of the digits. In addition, there is a need to understand numbers in writing and to associate them with verbal codes (Long, 2019). These skills are well illustrated in the Triple Coding Model introduced by Dehaene (1992).

The Triple Code Model of numerical cognition advocates the existence of three basic representation codes for number: Analog, verbal and symbolic representations (Dehaene, 1992). In the first of these representations, the number is represented with analog quantities such as the candles on the birthday cake, and 700 people present at the concert. All these remind us of the sense of number. In the second form of representation, numbers are represented verbally. For example, it is the expression of a numerical size such as "fifteen" in words. The third code is the symbolic one (here the digit format). The size or quantity is represented by a symbol called numerals. For example, they are single-digit numbers such as 3, 8, or multi-digit numbers such as 75 or 632 (Landerl, 2019).

The purpose of this study was to investigate primary school students' estimations of number magnitudes presented in triple coding model on number lines in relation to their mathematics achievement, calculation performance, and place value understanding.

\section{Methods}

The data were collected by Mathematics Achievement Test (MAT), Arithmetic Performance Test (APT), Place Value Test (PVT) and computerized Number Line Estimation tests (NLE). Computerized tests were developed by the researchers and consist of symbolic, verbal and visual (canonical and random dots) codes (NLE 0-10 and NLE 0-100) designed according to the triple coding model. The study group consisted of 214 second and third graders in the central district of a city in the Central Anatolia Region.

\section{Results}

Results showed that the estimation skills of third grade students in all tests on the number line are more linear than that of the second-grade students. The success of students in the lower and upper achievement group determined according to the mathematics achievement test at each grade level differs in terms of APT, PVT, NLE 0-10 and 0-100. It was observed that this differentiation was more pronounced especially in terms of APT and NLE tests. The higher the grade level, the wider the difference in achievement between the lower and upper groups. The Verbal 0-10 and Canonical 0-10 tests, which are designed according to the triple code model, with the 0-10 prediction range, predict mathematics achievement more. While Symbol 0-10 predominates the comprehension of place value, Canonical dots enumeration is the most predictor of arithmetic performance. Looking at predictive tests in the range of 0-100, Symbol 0-100 predicts mathematics achievement the most, while Symbol 0-100 and Random dot enumeration predict place value comprehension.

\section{Discussion and Conclusion}

The first of the findings obtained from the research is that third grade students' prediction skills on all tests on the number line are more linear than second grade students. In addition, third graders showed a more successful performance in their estimations made with all the representations of the number than the second grade. A similar situation has emerged in the comparisons between lower and upper achievement groups at the same grade level. The success of the students in the lower and upper groups differs in terms of Arithmetic 
Performance Test (APT), Place Value Test (PVT), Number Line 0-10 and 0-100. It was observed that this differentiation was more pronounced especially in terms of APT and PV tests. The higher the grade level, the wider the difference in achievement between the lower and upper groups.

Other findings obtained from the research showed that the Verbal 0-10 and Canonical 0-10 predict mathematics achievement most, among the tests in the 0-10 range designed according to the triple code model. While Symbol 0-10 predicts the comprehension of place value, Canonical dot enumeration is the most predictor of arithmetic performance. Looking at the tests in the range of 0-100, Symbol 0-100 predicts mathematics achievement the most, while Symbol 0-100 and Random dot enumeration predict place value comprehension. Symbol (0-100) and Canonical (0-100) variables predict students' arithmetic performance from the number line tests in the range of 0-100. When these findings are taken together, it can be stated that each of the Symbolic, Analog and Verbal representations in the triple coding model provides a basis for a scaffold in developing number magnitude.

As a result, it can be said that the findings generally support the view that the perceptions of numbers presented in different formats may cause differential performances in children. Therefore, pedagogically, it can be concluded that teaching with different forms of representations will be more beneficial for children's understanding of mathematics thoroughly. 